\title{
Impact of cloud microphysics and cumulus parameterization on simulation of heavy rainfall event during 7-9 October 2007 over Bangladesh
}

\author{
M Mahbub Alam \\ Theoretical Division, SAARC Meteorological Research Centre (SMRC), Dhaka, Bangladesh. \\ Department of Physics, Khulna University of Engineering 83 Technology, Khulna, Bangladesh. \\ e-mail: mdalam60@gmail.com malam@saarc-smrc.org
}

In the present study, the Advanced Research WRF (ARW) version 3.2.1 has been used to simulate the heavy rainfall event that occurred between 7 and 9 October 2007 in the southern part of Bangladesh. Weather Research and Forecast (WRF-ARW version) modelling system with six different microphysics (MP) schemes and two different cumulus parameterization (CP) schemes in a nested configuration was chosen for simulating the event. The model domains consist of outer and inner domains having 9 and $3 \mathrm{~km}$ horizontal resolution, respectively with 28 vertical sigma levels. The impacts of cloud microphysical processes by means of precipitation, wind and reflectivity, kinematic and thermodynamic characteristics of the event have been studied. Sensitivity experiments have been conducted with the WRF model to test the impact of microphysical and cumulus parameterization schemes in capturing the extreme weather event. NCEP FNL data were used for the initial and boundary condition. The model ran for $72 \mathrm{~h}$ using initial data at 0000 UTC of 7 October 2007. The simulated rainfall shows that WSM6-KF combination gives better results for all combinations and after that Lin-KF combination. WSM3-KF has simulated, less area average rainfall out of all MP schemes that were coupled with KF scheme. The sharp peak of relative humidity up to $300 \mathrm{hPa}$ has been simulated along the vertical line where maximum updraft has been found for all MPs coupled with KF and BMJ schemes. The simulated rain water and cloud water mixing ratio were maximum at the position where the vertical velocity and reflectivity has also been maximum. The production of rain water mixing ratio depends on MP schemes as well as CP schemes. Rainfall depends on rain water mixing ratio between 950 and $500 \mathrm{hPa}$. Rain water mixing ratio above $500 \mathrm{hPa}$ level has no effect on surface rain.

\section{Introduction}

Widespread floods associated with heavy precipitation are common in the southern and southeastern regions of Bangladesh during post monsoon season (October-November). Precipitating weather systems in combination with strong wind, hail and flooding have impact and influence on the broad range of activities. During the monsoon season (June-September), southeastern and northeastern parts of Bangladesh receive heavy rainfall. The strong moisture-laden winds from the Bay of Bengal interact with the topography, causing heavy precipitation over this region. Therefore, heavy precipitation, its timing, location and intensity, is certainly a key parameter in weather

Keywords. WRF-ARW model; microphysics; cumulus parameterization; heavy rainfall. 
prediction and has significance on operational hydrology. Rainfall is highly variable in space and time and is strongly influenced by orographic forcing.

Etherton and Santos (2008) showed that WRF forecasts vastly overpredicted the areas of heavy precipitation over south Florida. This overprediction of heavy rains is a likely cause for the higher bias of the WRF forecasts. Yun-Fei et al. (2012) studied the evaluation of hydrometeors based on TMI observations inside the typhoon centre. Their results indicate that the WRF model underestimated the amount and area of liquid and ice hydrometeors inside the typhoon center. Rajeevan et al. (2010) studied the sensitivity of four different cloud microphysics schemes for the simulations of a severe thunderstorm over southeast India. They have found the large variations of updraft/downdraft cores, surface rainfall and hydrometeor profiles among the four MP schemes. They have also shown that simulated updraft and downdrafts were weaker than observed and the simulated results of Thompson scheme were closer to observations. Uma and Rao (2009) studied the characteristics of vertical velocity cores in different convective systems observed over Gadanki by using Indian MST radar data. They have found that in the upper troposphere, strong updrafts of the order of $15-20 \mathrm{~ms}^{-1}$ have been observed in deep convective systems. They have also shown that in all types of convection the downdrafts are generally weaker.

In this paper, 12 experiments have been conducted by using different microphysics (e.g., Kessler, Lin et al., WSM 3-class simple ice scheme, Ferrier (New Eta), WSM 6-class graupel scheme and Thompson graupel) in combination of Kain-Fritsch (KF) and Betts-Miller-Janjic (BMJ) cumulus parameterization schemes with 0000 UTC of 7 October 2007 initial condition to study which microphysics and cumulus parameterization schemes are better for the simulation of heavy rainfall event during 7-9 October 2007.

\section{Synoptic situation}

A low pressure system was formed over west central Bay and adjoining northwest Bay on 7 October 2007. The system intensified into a well marked low and moved in a northwesterly direction. Under its influence deep convection took place over north Bay. The well marked low over westcentral Bay and adjoining northwest Bay became less important on 8 October 2007. On the same day another low was formed over southeastern part of Bangladesh and adjoining Bay area. The system intensified rapidly into a land depression over southern part of Bangladesh and adjoining areas

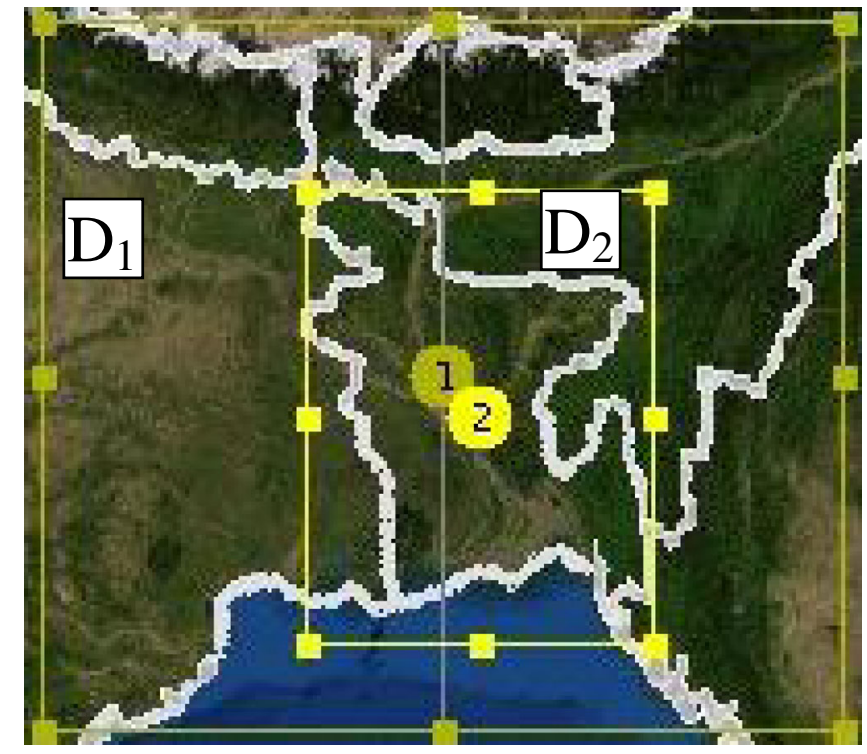

Figure 1. Nested domain for running WRF model.

and the system moved in a north-northwesterly direction. Under its influence steep pressure gradient persisted over North Bay. The land depression over Barisal and adjoining areas moved further north-northwesterly direction and lay over Bogra and adjoining areas and moved further again in a north-northwesterly direction and weakened gradually by giving precipitation. Monsoon was active over Bangladesh and moderate to strong over North Bay.

\section{Model description and numerical experiments}

The Advanced Research WRF (ARW) model, version 3.2.1 was utilized in this study. The ARW system consists of fully compressible non-hydrostatic equations with different prognostic variables. The model is run at two nested domains (figure 1) $9 \mathrm{~km}$ inner and $3 \mathrm{~km}$ outer resolutions and 28 vertical sigma levels over Bangladesh and surrounding areas using the boundary conditions of NCEP. The detailed configuration of the WRF Model physics, dynamics and domain is given in table 1 .

Microphysics consists of explicitly resolved water vapour, cloud and precipitation processes. In this research, six different microphysical schemes have been used to simulate the heavy rainfall event during 7-9 October 2007. The details of six different microphysical schemes are given below:

Kessler scheme: The Kessler scheme is a simple warm cloud scheme that includes water vapour, 
Table 1. WRF model and domain configurations.

\begin{tabular}{|c|c|}
\hline Dynamics & Non-hydrostatic \\
\hline Number of domains & 2 \\
\hline Central points of the domain & $\begin{array}{l}\text { D1: Central Lat.: } 24^{\circ} \mathrm{N} \text {, Central Long.: } 90^{\circ} \mathrm{E} \\
\text { D2: Central Lat.: } 23.51^{\circ} \mathrm{N} \text {, Central Long.: } 90.49^{\circ} \mathrm{E}\end{array}$ \\
\hline Horizontal grid distance & 1) Outer domain $-9 \mathrm{~km}, 2$ ) Inner domain $-3 \mathrm{~km}$ \\
\hline Integration time step & $45 \mathrm{~s}$ \\
\hline Number of grid points & $\begin{array}{l}\text { D1: X-direction } 120 \text { points, Y-direction } 107 \text { points } \\
\text { D2: X-direction } 157 \text { points, Y-direction } 205 \text { points }\end{array}$ \\
\hline Map projection & Mercator \\
\hline Horizontal grid distribution & Arakawa C-grid \\
\hline Nesting & One way \\
\hline Vertical co-ordinate & Terrain-following hydrostatic-pressure co-ordinate (28 sigma levels up to $100 \mathrm{hPa}$ ) \\
\hline Time integration & 3rd order Runge-Kutta \\
\hline Spatial differencing scheme & 6 th order centered differencing \\
\hline Initial conditions & Three-dimensional real-data $\left(\mathrm{FNL}: 1^{\circ} \times 1^{\circ}\right)$ \\
\hline Lateral boundary condition & Specified options for real-data \\
\hline Top boundary condition & Gravity wave absorbing (diffusion or Rayleigh damping) \\
\hline Bottom boundary condition & Physical or free-slip \\
\hline Diffusion and damping & Simple diffusion \\
\hline Microphysics & $\begin{array}{l}\text { 1) Kessler scheme (Kessler 1969) } \\
\text { (2) Lin et al. (1983) scheme } \\
\text { (3) WSM3-class scheme (Hong et al. 2004) } \\
\text { (4) Eta (Ferrier) scheme (Ferrier et al. 1995) } \\
\text { (5) WSM 6-class graupel scheme (Hong and Lim 2006) } \\
\text { (6) Thompson graupel scheme (Thompson et al. 2004). }\end{array}$ \\
\hline Radiation scheme & Dudhia (1989) for short wave radiation/RRTM long wave Mlawer et al. (1997) \\
\hline Surface layer & Monin-Obukhov similarity theory scheme (Hong and Pan 1996) \\
\hline Land surface parameterization & 5-layer thermal diffusion scheme (Ek et al. 2003) \\
\hline Cumulus parameterization schemes & $\begin{array}{l}\text { 1) Kain-Fritsch scheme (KF), (Kain and Fritsch 1990, 1993; Kain 2004) } \\
\text { 2) Betts-Miller-Janjic (BMJ), (Janjic 1994, 2000) }\end{array}$ \\
\hline PBL parameterization & Yonsei University scheme (YSU) (Hong et al. 2006) \\
\hline
\end{tabular}

cloud water and rain. The microphysical process consists of the production, fall and evaporation of rain, the accumulation and autoconversion of cloud water and the production of cloud water from condensation.

Lin et al. scheme: Lin et al. scheme includes six classes of hydrometeors: water vapour, cloud water, rain, cloud ice, snow and graupel. This is a sophisticated microphysics scheme in WRF, and it is most suitable for use in research studies.

\section{WRF Single-Moment 3-class (WSM3)} scheme: The WSM microphysics scheme includes ice sedimentation and other new ice-phase parameterizations. In this scheme an analytical relation is used for ice number concentration that is based on ice mass content rather than temperature. The WSM3 scheme predicts three categories of hydrometers: water vapour, cloud water and rain water mixing ratio, which is so-called simple-ice scheme. This scheme is computationally efficient for the inclusion of ice processes, but lacks super cooled water and gradual melting rates.
Ferrier (Eta) scheme: Ferrier scheme predicts changes in water vapour and condensate in the forms of cloud water, rain, cloud ice and precipitation ice. Local storage arrays retain first-guess information that extract contributions of cloud water, rain, cloud ice and precipitation ice of variable density in the form of snow, graupel or sleet. The density of precipitation ice is expected from a local array that stores information on the total growth of ice by vapour deposition and accretion of liquid water. Sedimentation is treated by partitioning the time averaged flux of precipitation into a grid box between local storage in the box and fall out through the bottom of the box.

WSM6 scheme: WSM6 scheme includes vapour, rain, snow, cloud ice, cloud water and graupel in six different arrays. A new method for representing mixed-phase particle fall speeds for the snow and graupel by assigning a single fall speed to both that is weighed by the mixing ratios, and applying that fall speed to both sedimentation and accumulation processes is introduced 
(Dudhia et al. 2008). Of the three WSM schemes, the WSM6 scheme is the most suitable for cloudresolving grids, considering the efficiency and theoretical backgrounds (Hong and Lim 2006).

Thompson et al. scheme: A bulk microphysical parameterization (BMP) developed for use with WRF or other mesoscale models. The snow size distribution depends on both ice water content and temperature and is represented as a sum of exponential and gamma distributions. Furthermore, snow assumes a non-spherical shape with a bulk density that varies inversely with diameter as found in observations.

Six microphysical schemes in combination with two cumulus parameterization schemes have been used to study the heavy rainfall event. The details of Kain-Fritsch and Betts-Miller-Janjic cumulus parameterization schemes are given below:

Kain-Fritsch (KF) scheme: In the KF scheme, condensates in the updraft are converted into precipitation when their amount exceeds threshold value. In this scheme the convection consumes the convective available potential energy in a certain time scale. The KF scheme also includes the shallow convection other than deep convection. The shallow convection creates non-precipitable condensates and the shallowness of the convection is determined by a vertical extent of the cloud layer that is known by a function of temperature at LCL of rising air parcel.

Betts-Miller-Janjic (BMJ) scheme: The BMJ cumulus parameterization scheme is a nudging type adjustment of temperature and humidity in grid scale. The scheme adjusts the sounding towards a pre-determined, post-convective profile derived from climatology. This post-convective profile has been defined by points at the cloud base, cloud top and freezing level. In this scheme there is no explicit updraft or downdraft and no cloud detrainment occurs. Convection is initiated when soundings are moist through a deep layer and when convective available potential energy (CAPE) and convective cloud depth thresholds are exceeded.

A total of 12 experiments were conducted by using six different microphysics schemes coupling with two different cumulus parameterization schemes. Final Reanalysis $(\mathrm{FNL})$ data $\left(1^{\circ} \times 1^{\circ}\right)$ from National Centre for Environment Prediction (NCEP) is used as initial and lateral boundary conditions (LBCs) which are updated at six hourly intervals. The model is integrated for 72 -h during 0000 UTC of 7 October to 0000 UTC of 10 October 2007.

\section{Results and discussions}

Simulated rainfall, wind at $10 \mathrm{~m}$ and $850 \mathrm{hPa}$ level, reflectivity at $850 \mathrm{hPa}$ level, maximum vertical velocity are discussed in the following subsection. Relative humidity, cloud water mixing ratio, rain water mixing ratio, reflectivity, and vorticity simulated by six MPs coupling with two CPs are plotted along the line of maximum vertical velocity and also discussed in the following subsections. In order to examine the differences in the simulated cloud structure, space-averaged and time-averaged vertical profiles of water vapour, cloud water, rain water, graupel, snow and ice mixing ratio $(\mathrm{g} / \mathrm{kg})$, and vorticity were calculated once every three hours on 7 and 8 October 2007.

\subsection{Rainfall}

The TRMM surface rainfall measured by TRMM's precipitation radar and rain gauge rainfall observed by Bangladesh Meteorological Department (BMD) during 7-9 October is presented in figure $2(\mathrm{a}-\mathrm{f})$. The rainfall was observed on 7 October (figure 2a) in the southern and southeastern parts but TRMM indicates that the rainfall occurred (figure 2d) all over Bangladesh and also less rain in the southeastern parts of Bangladesh. All MPs coupling with KF and BMJ CP schemes (figure 3) failed to simulate rain in the southwestern parts and much more rain is simulated in the eastern parts of the country on this day. On 8 October, the maximum observed rainfall is found in Sitakundu-Sandwip-Feni region (figure 2b) but TRMM indicates that the maximum rain occurred in the central region (figure 2e) of the country. TRMM failed to indicate the scenario of heavy rain events in the eastern side of the country on 8 October 2007. Kessler-KF simulated two patches of heavy rain, one in the southeast and other patch in the northwest of the observed rain on 8 October. LinKF, WSM6-KF, Ferrier-KF, and Thompson-KF have simulated (figure 4) the heavy rain event but shifted towards northwest from the observed rainfall position. WSM3-KF simulated less intensity of heavy rainfall but shifted towards west from the observed heavy rainfall position. All MPs coupling with BMJ CP schemes failed to simulate (figure 4) heavy rainfall in Sitakundu-SandwipFeni region. On 9 October, the rainfall pattern shifted towards north and maximum rainfall was observed in the north and northwestern parts of Bangladesh (figure 2e). The TRMM result (figure 2f) also shows that maximum rainfall occured in the northwestern part of Bangladesh. The shifting pattern of rainfall for all MPs coupling with KF CP scheme (figure 5) matched 

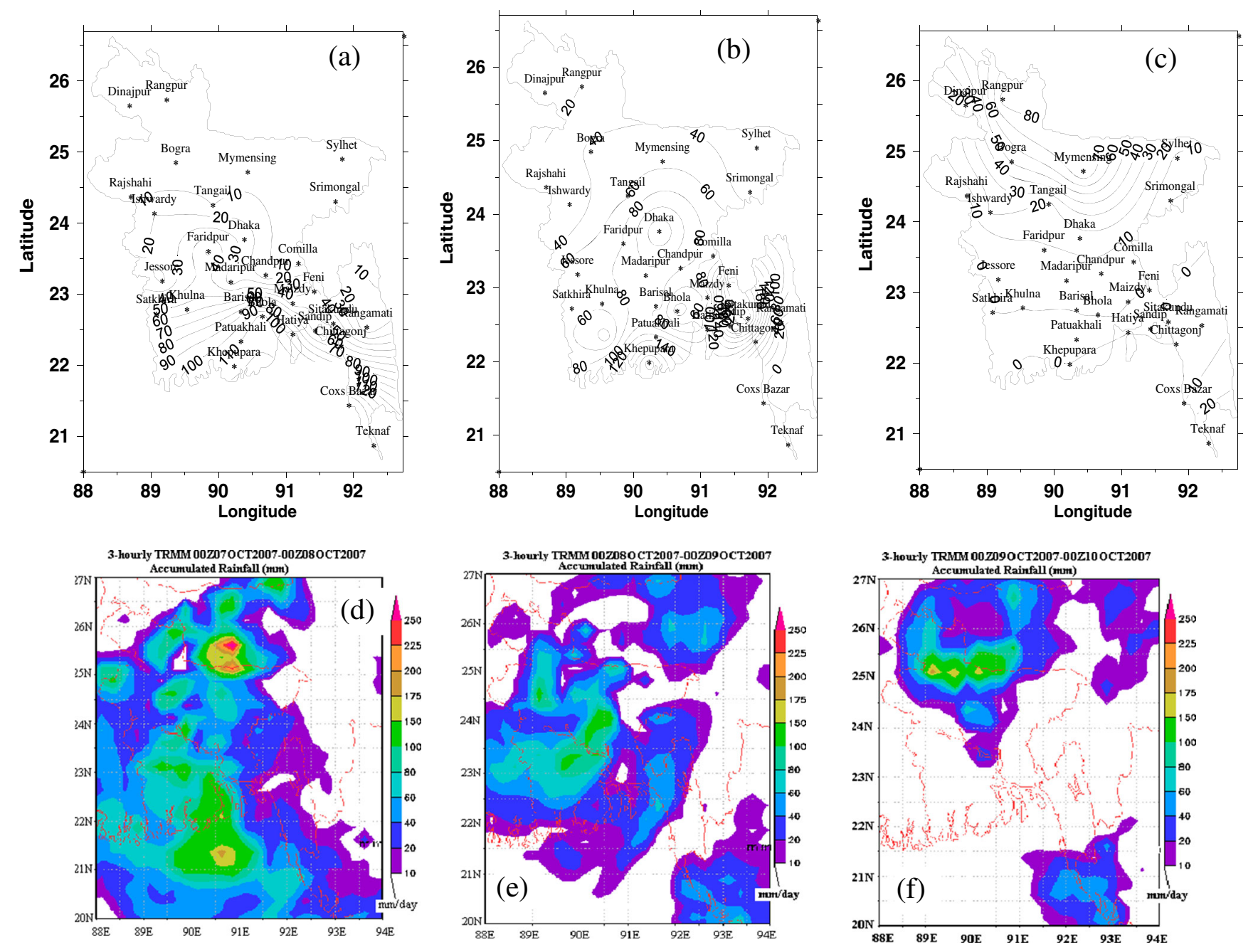

Figure 2. Daily rainfall (a-c) observed and (d-f) TRMM during 7-9 October 2007, respectively.

with observed value but simulated rainfall was much higher than that of observed rainfall. LinBMJ, WSM6-BMJ, Thompson-BMJ and FerrierBMJ have simulated much more rain (figure 5) in the southwestern parts of observed rainfall on 9 October. WSM3-BMJ simulated rainfall is comparable with observed rainfall but shifted towards southwest from the observed position.

The observed, TRMM and WRF model simulated daily rainfall on 7 and 8 October 2007 and 3 hourly area average rainfall using KF and BMJ schemes are presented in figure $6(\mathrm{a}-\mathrm{d})$. The area of rainfall was shifted towards north due to the movement of the mesoscale convective system (MCS). For that reason the area was considered for averaging the model simulated, observed and TRMM observational rainfall for 7,8 and 9 October are $21^{\circ}-23.5^{\circ} \mathrm{N}$ and $89^{\circ}-92.5^{\circ} \mathrm{E}, 21.5^{\circ}-25^{\circ} \mathrm{N}$ and $89^{\circ}-$ $92.5^{\circ} \mathrm{E}$ and $24^{\circ}-25.5^{\circ} \mathrm{N}$ and $89^{\circ}-91.5^{\circ} \mathrm{E}$, respectively. It can be seen from figure $6(\mathrm{a}$ and $\mathrm{b})$ that the area average daily TRMM observational rainfall was much higher on 7 October and much lower than that of observed rainfall by BMD rain gauge stations on 8 October. The simulated area average daily rainfall using BMJ scheme coupling with all MPs on 7 and 8 October was much less than that of the observed rainfall. The simulated area average daily rainfall using $\mathrm{KF}$ scheme coupling with all MPs are comparable on 7 October and less than that of observed rainfall on 8 October. The area average daily rainfall on 7 October using LinKF combination was almost equal and less than observed rainfall on 8 October but higher than all other combinations. It has also been observed that WSM6-KF gives better rainfall after Lin-KF combination.

WSM3 simulated less daily rainfall (area average) out of all MP schemes coupling with KF scheme. Three-hourly area average rainfall pattern signifies that at the time (2100UTC) of observed maximum rainfall on 7 October all MPs coupling with KF scheme also simulated maximum amount of rain but the simulated rain is higher than the observed rain. Maximum area average observed rain was found during $0900-1200$ UTC on 8 October. TRMM and all MP schemes in combination of 

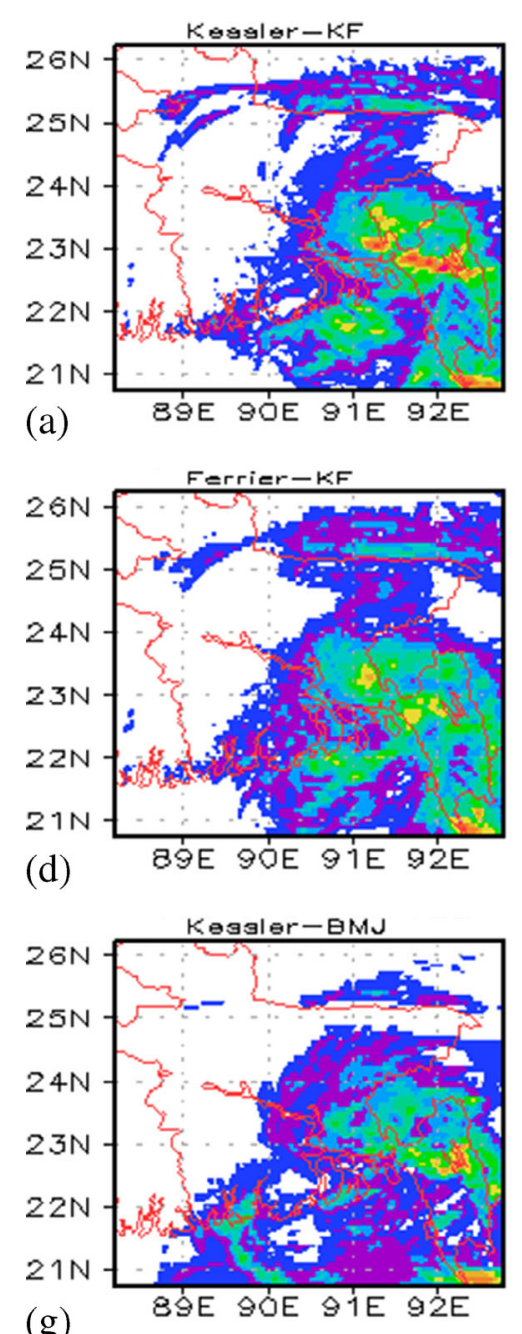

(g)

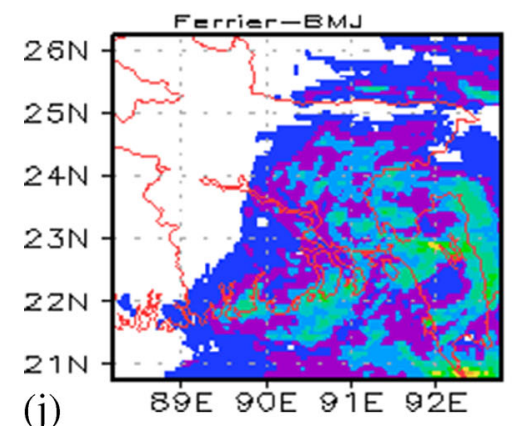

(j)
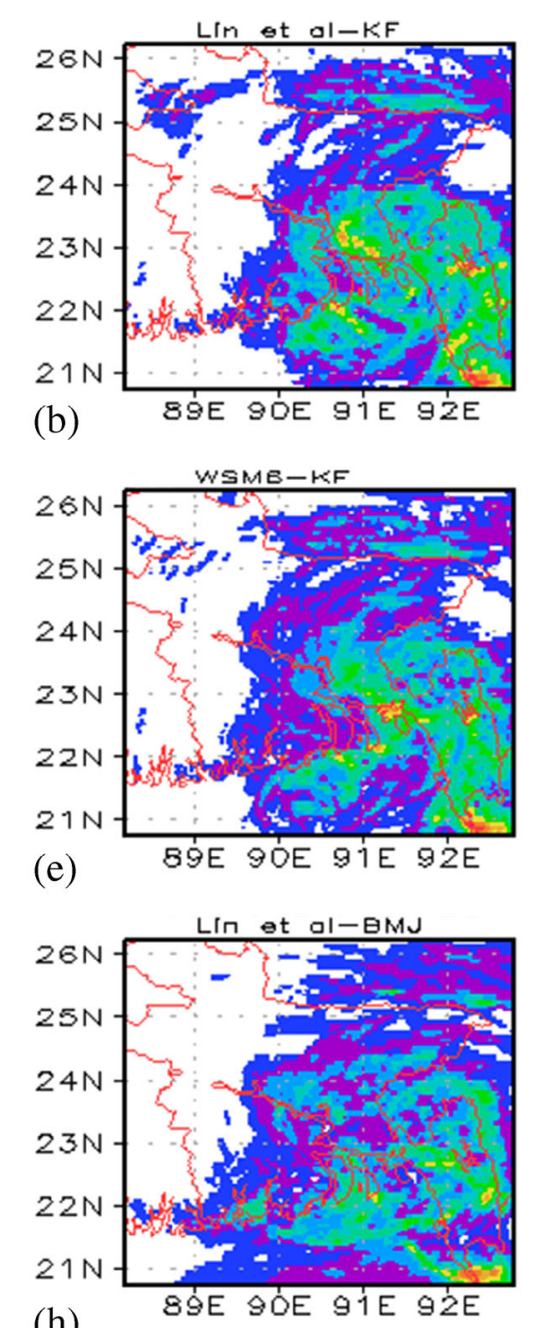

(h)

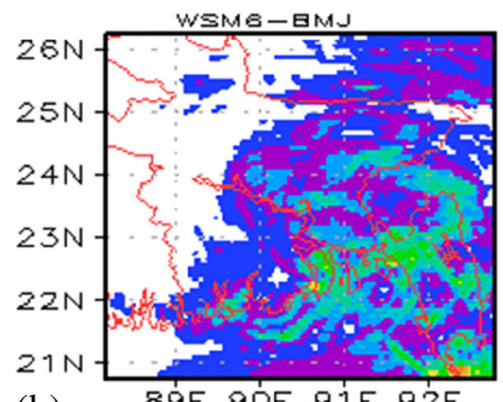

(k)
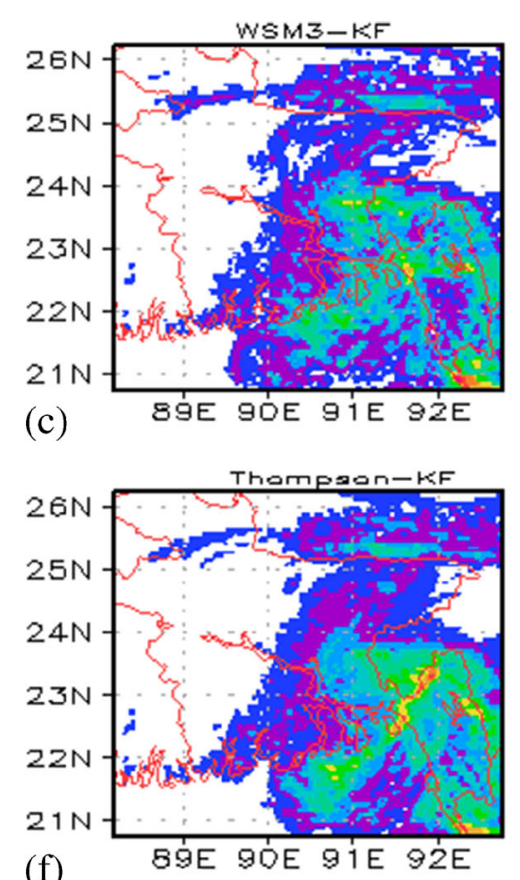

(f)

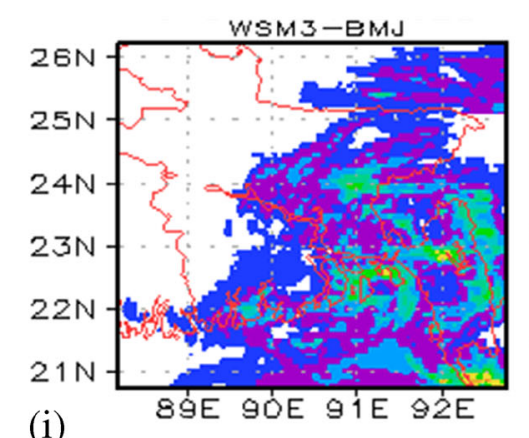

(i)

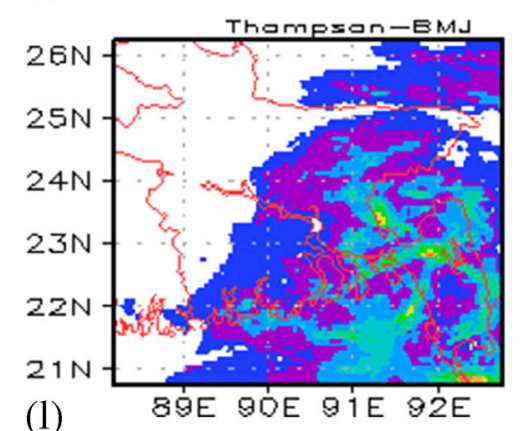

Figure 3. WRF model simulated rainfall (mm) using Kessler, Lin et al., WSM3, Ferrier, WSM6 and Thomson schemes coupling with (a-f) KF and (g-l) BMJ schemes of heavy rainfall event of 7 October 2007.

$\mathrm{KF}$ and BMJ schemes fail to simulate significant amount of rain during that period. Lin-KF combination has simulated the highest amount of rain but still much less than the observed rainfall.

\subsection{Winds}

Model simulated $850 \mathrm{hPa}$ level winds at 0000 and 1200 UTC of 8 October 2007 using different MP schemes coupling with $\mathrm{KF}$ and BMJ schemes with the initial condition at 0000 UTC of
7 October are shown in figures $7(\mathrm{a}-1)$ and $8(\mathrm{a}-\mathrm{l})$, respectively. Both the figures suggest that the cyclonic circulation exists in all combinations of MP schemes coupling with KF and BMJ schemes at $850 \mathrm{hPa}$ level. The figures also suggest that the maximum wind has been simulated in the southeastern to northeastern parts of Bangladesh and minimum wind has also been simulated at the southwestern region of the cyclonic circulation. KF scheme coupling with different MP schemes simulated greater wind speed than that of BMJ 

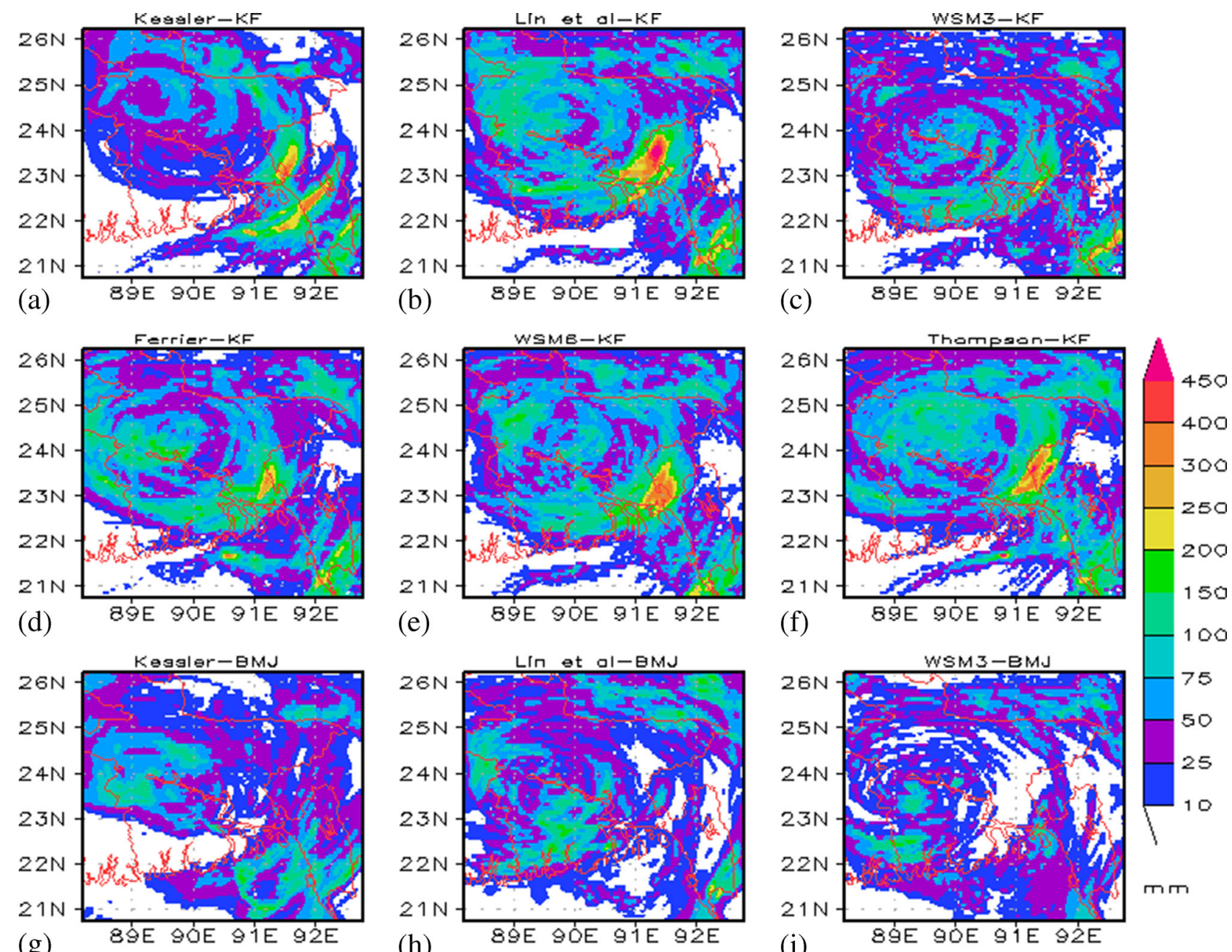

(g)
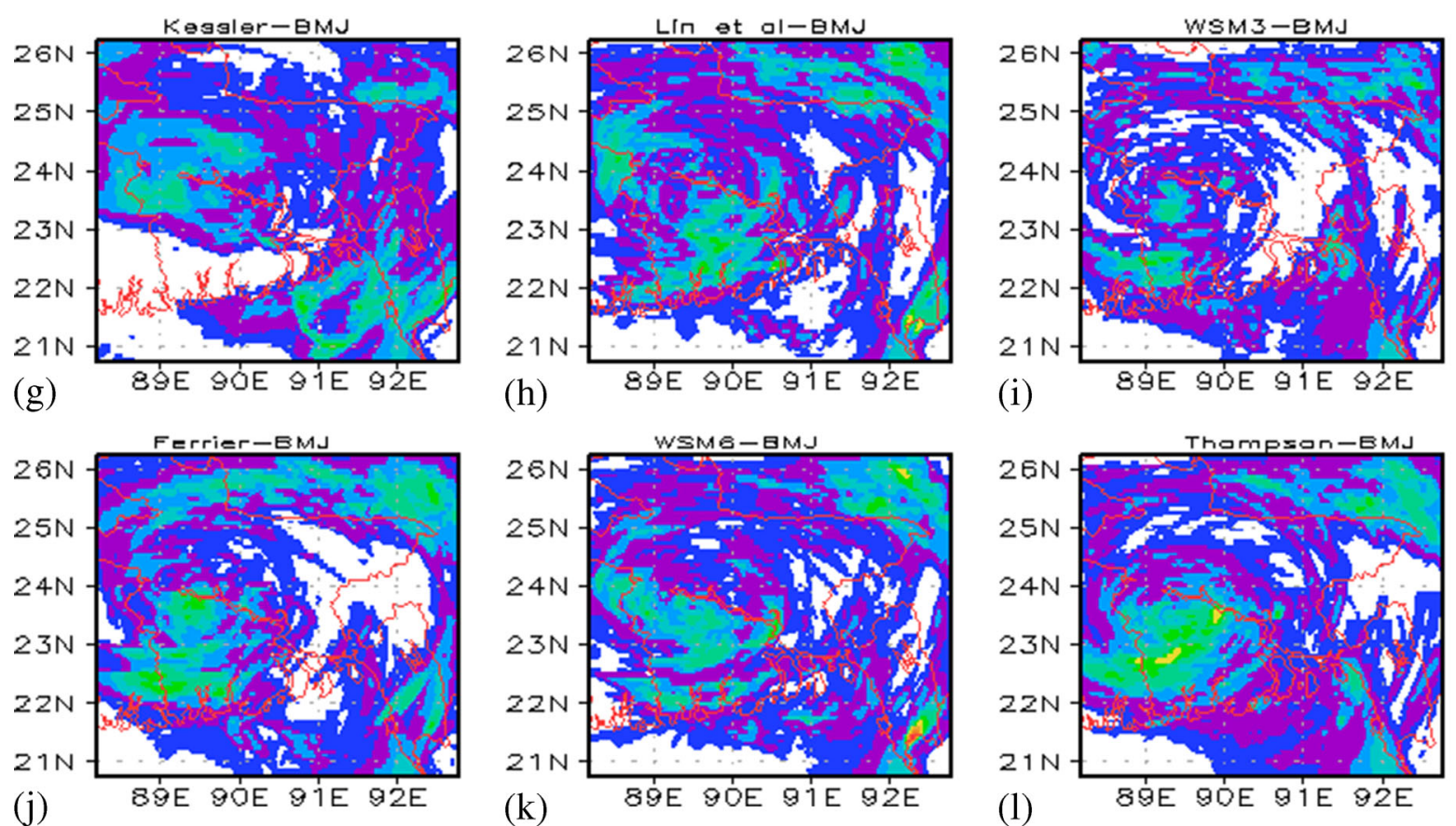

Figure 4. Same as figure 3, but for 8 October 2007.

scheme. It has also been observed that the cyclonic circulation shifted towards northwestward direction. Due to the movement of cyclonic circulation in the northwestward direction, the rainfall pattern also shifted towards that direction. The simulated shifting rainfall pattern has found to match with the BMD observational rainfall.

\subsection{Vertical velocity}

The maximum updraft and downdraft at inner domain D2 on 7 and 8 October 2007 using different MPs coupling with KF and BMJ schemes are presented in figures 9 and 10, respectively. The maximum updraft at outer domain D1 (not shown) was found to be always less than that of domain D2 in all combinations of MPs and CP schemes. The maximum updrafts simulated times and positions were different in different combinations of MPs and CP schemes (figures 9 and 10). The maximum updraft simulated 16.2, 26, 19.5, $17.1,25.3$ and $22.9 \mathrm{~ms}^{-1}$ at the times of 0900 , 1500, 1200, 2100, 0900 and 0900 UTC (figure 9) of 7 October by using Kessler-KF, Lin-KF, 

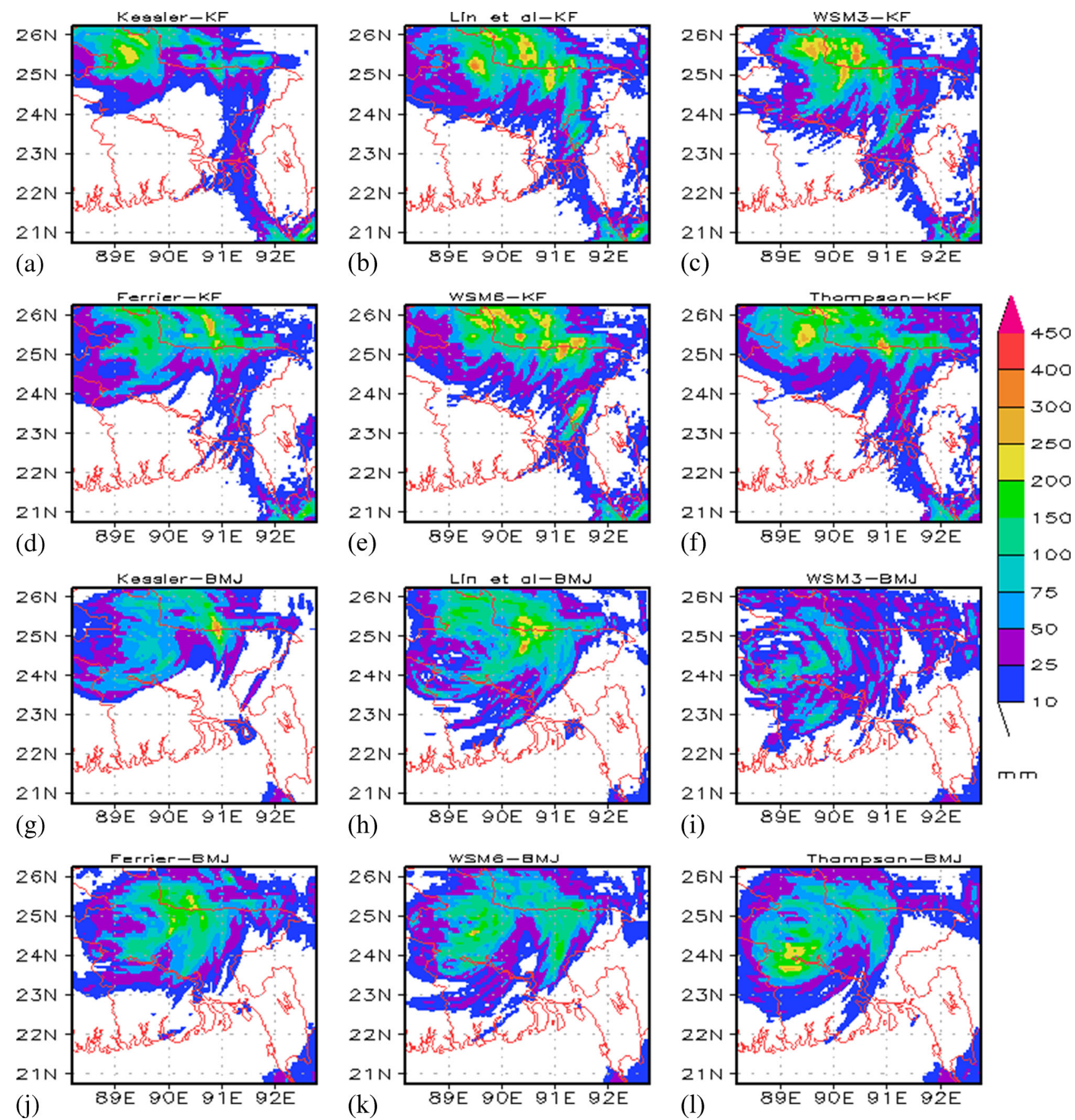

Figure 5. Same as figure 3, but for 9 October 2007.

WSM3-KF, Ferrier-KF, WSM6-KF and Thomson-KF combination. The maximum updraft simulated 10.6, 25.7, 16.4, 15.6, 21.3 and $16.8 \mathrm{~ms}^{-1}$ at 1200 UTC by six different MPs coupling with BMJ scheme. The maximum updraft was simulated by Lin-KF, WSM6-KF, Thompson-KF, Lin-BMJ and WSM6-BMJ at around 300-150 $\mathrm{hPa}$, by Kessler-KF, and WSM3-KF at around 400-200 hPa and Ferrier-KF, Ferrier-BMJ, WSM3-BMJ and Thompson-BMJ at around 500-300 hPa on 7 October 2007 (figure 9).
The simulated maximum updraft on 8 October using different MP schemes in combination with KF scheme were 13.1, 17.7, 14.97, 15.1, 18.3 and $19.3 \mathrm{~ms}^{-1}$ at the times of $0600,0900,0900,0300$, 2100 and 1800 UTC (figure 10). The maximum updraft $8.3,12.6,7.2,11.7,18.2$ and $12.4 \mathrm{~ms}^{-1}$ has also been simulated for all MP schemes coupling with BMJ scheme on 8 October 2007 (figure 10). On both the days the KF scheme simulated much more updraft than that of BMJ scheme. It was also observed that the simulated updraft was much less 

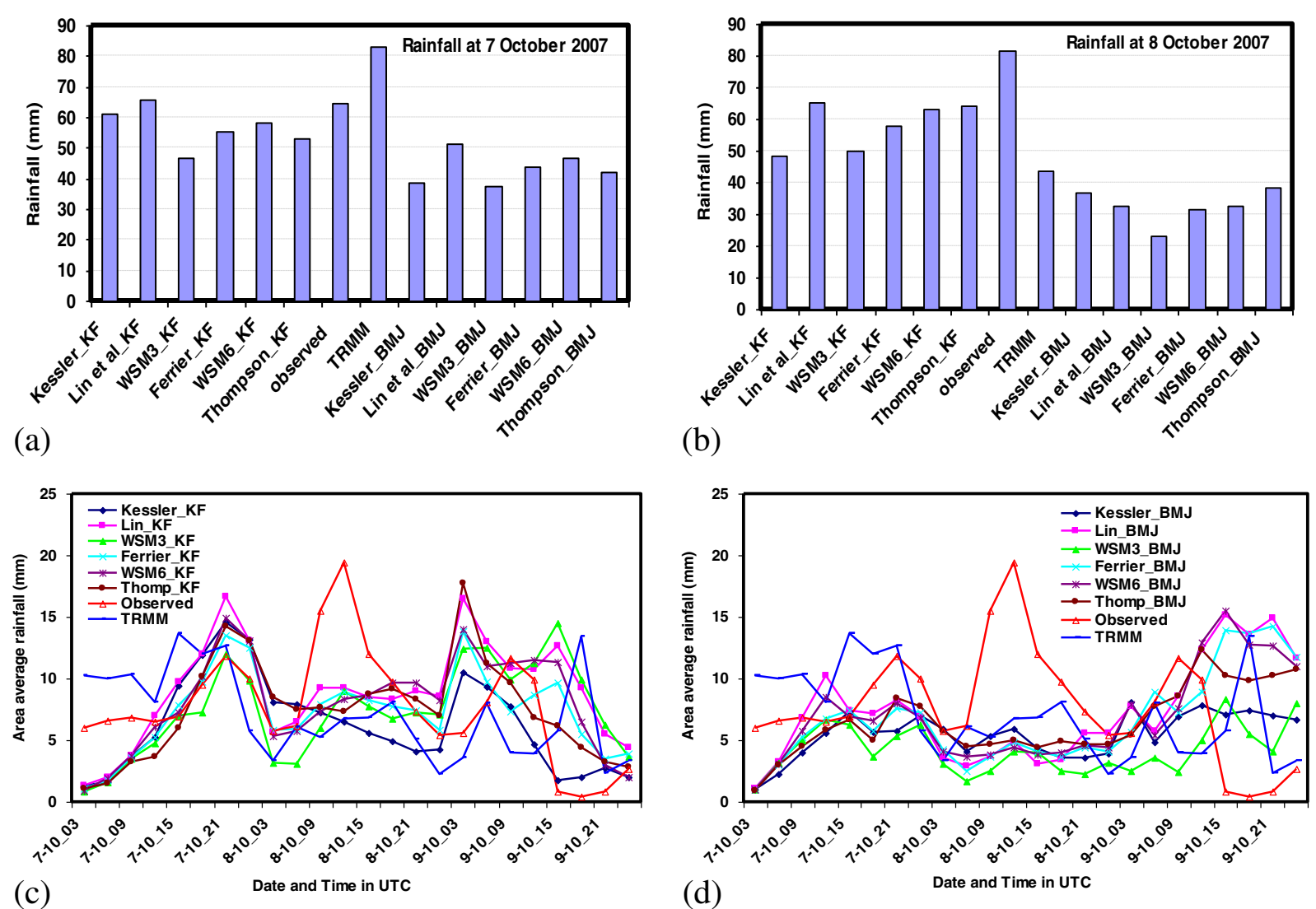

Figure 6. Model simulated, TRMM and observed (a and b) area average daily rainfall on 7 and 8 October and (c and $\mathbf{d}$ ) 3-hourly area average rainfall using six different MPs coupling with KF and BMJ schemes, respectively.

by Kessler-BMJ on 7 and 8 October and WSM3BMJ on 8 October 2007. The downdraft was generally weaker but was seen throughout the depth of the troposphere and maximum updraft was seen in the middle and upper troposphere.

\subsection{Relative humidity}

The relative humidity (contour) along the line of maximum updraft at domain D2 using different MPs coupling with KF and BMJ schemes on 7 and 8 October 2007 are presented in figures 9 and 10, respectively. The simulated relative humidity, where vertical velocities and reflectivity $(\mathrm{dbz})$ have been maxima, exceeds $90 \%$ for all MPs coupling with KF and BMJ schemes on 7 and 8 October. The sharp peak, up to $300 \mathrm{hPa}$ level, of relative humidity has been simulated for all MPs coupling with KF and BMJ schemes on 7 and 8 October along the vertical line where maximum updraft occurs.

\subsection{Reflectivity}

The horizontal distribution of reflectivity (shaded) at $850 \mathrm{hPa}$ on 0000 and 1200 UTC of 8 October using different MP schemes coupling with KF and BMJ schemes are presented in figures 7 and 8, respectively. Figures 7 and 8 point out that the simulated horizontal reflectivity on 7 and 8 October for all MPs coupling with KF scheme were much more than that of BMJ scheme. The maximum reflectivity was simulated in the eastern and southeastern sides of the circulation centre by six different MP schemes coupling with CP schemes. The vertical structure of reflectivity (shaded) have been plotted along the line of maximum vertical velocities on 7 (figure 11) and 8 (figure 12) October 2007 using different MP schemes coupling with $\mathrm{KF}$ and BMJ schemes.

In case of Lin et al. Ferrier, WSM6, and Thompson MP, the reflectivity $00 \mathrm{dBZ}$ was above $550 \mathrm{hPa}$ but for WSM3 and Kessler schemes the reflectivity $00 \mathrm{dBZ}$ was above 100 and 200 $\mathrm{hPa}$, respectively. The reflectivity pattern indicates that the cloud has been simulated by WSM3 and Kessler schemes up to 100 and $200 \mathrm{hPa}$ level and all other MP schemes have simulated cloud up to $550 \mathrm{hPa}$ level. The high values of reflectivity above the freezing level indicate the existence of supercooled liquid raindrops or large ice particles. The maximum reflectivity has been simulated in two separate cloud clusters (figure 11a and b) 

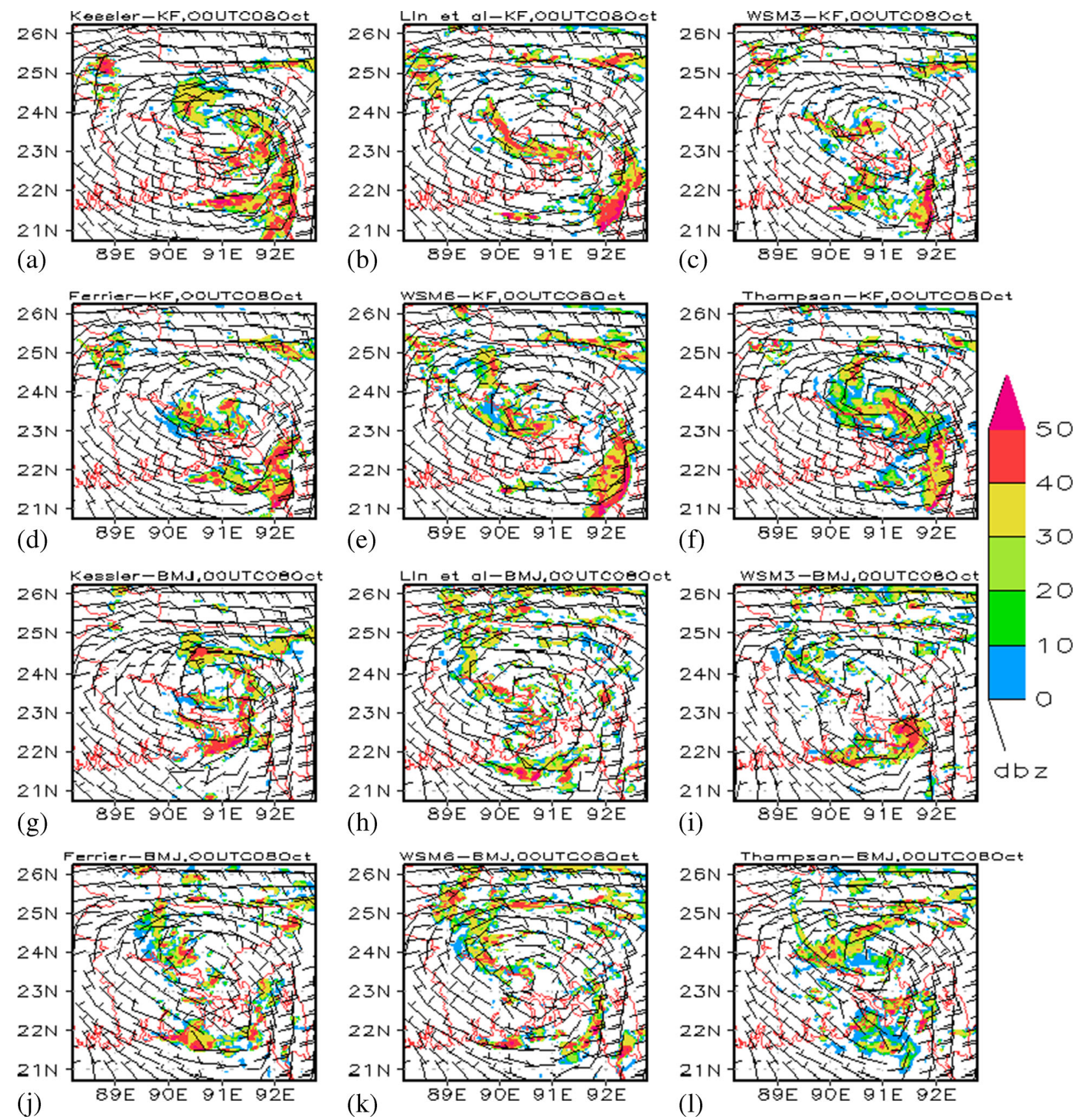

Figure 7. Model simulated $850 \mathrm{hPa}$ level wind (barb) and reflectivity (shaded) at 0000 UTC 08 October 2007 using Kessler, Lin et al., WSM3, Ferrier, WSM6 and Thomson schemes coupling with (a-f) KF and (g-l) BMJ schemes of heavy rainfall event.

where simulated updraft has also been maximum (figure 9a and b) by Kessler-KF and Lin-KF combinations. Figures 11 and 12 show that for all combination of MP schemes and CP schemes where reflectivity has been maximum, the updraft has also been maximum (figures 9 and 10).

\subsection{Vorticity}

The vertically integrated area and time averaged vorticity $\left(\times 10^{-5} / \mathrm{s}\right)$ on 7 and 8 October 2007 for six
MP schemes coupling with KF and BMJ schemes are presented in figure $13(\mathrm{a}-\mathrm{d})$. The area average positive vorticity simulated from 950 to 300 $\mathrm{hPa}$ for all MP schemes coupling with $\mathrm{KF}$ and BMJ schemes. For all MP schemes coupling with $\mathrm{CP}$ schemes, the maximum vorticity has been simulated at 900-800 hPa levels. Two maxima of vorticity have been simulated for all MPs in combination of KF scheme on 7 and 8 October and BMJ scheme on 7 October 2007.

Significant differences of vorticity were simulated among all the MP schemes. Kessler-KF simulated 

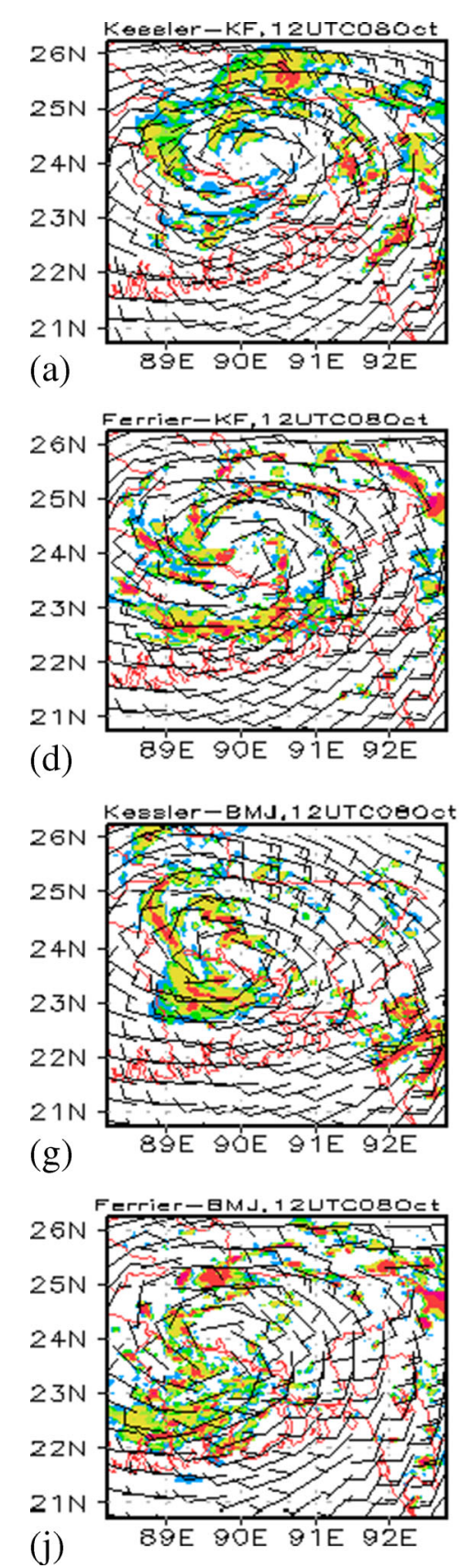
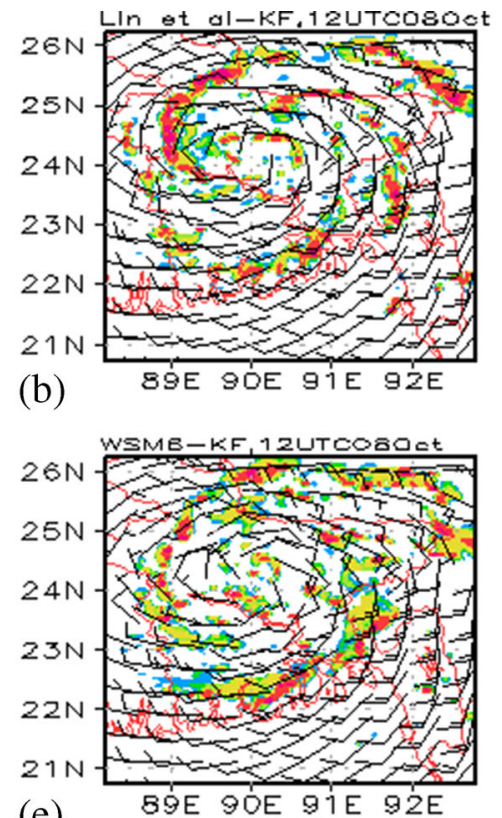

(e)

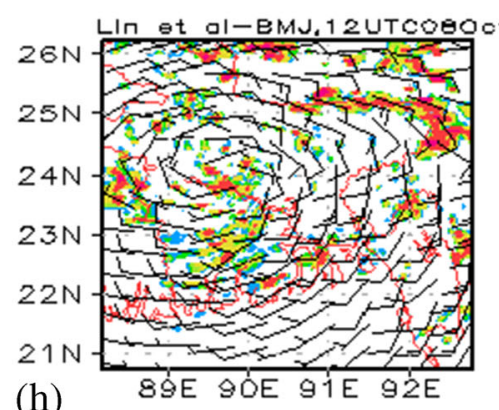

(h)

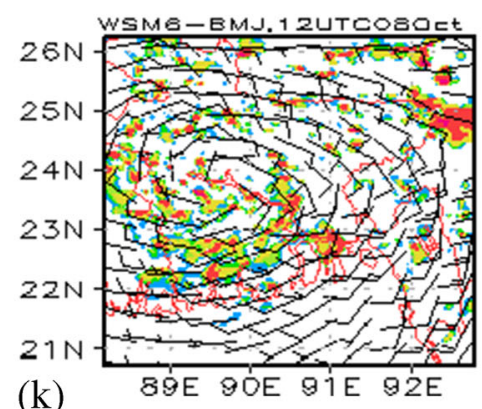

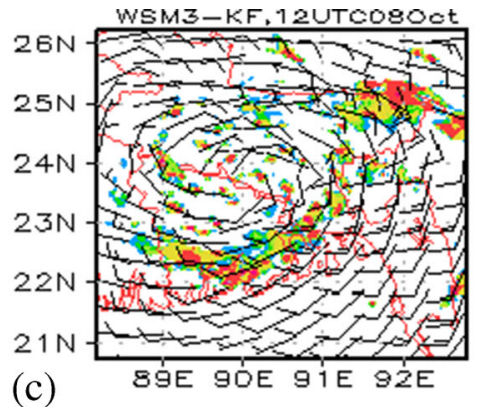

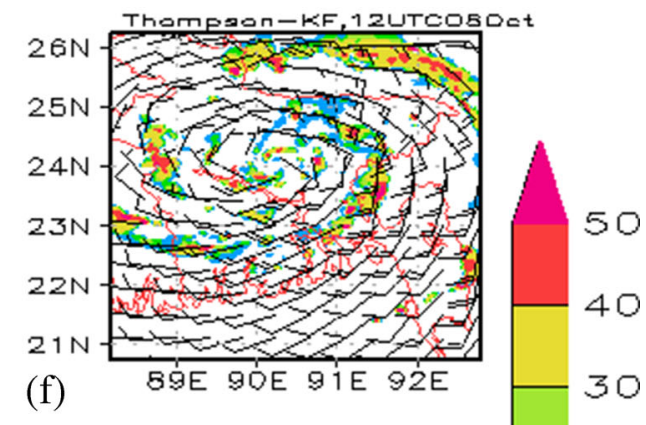

(f)

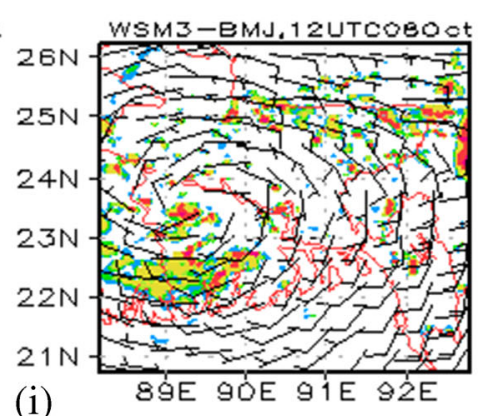

(i)

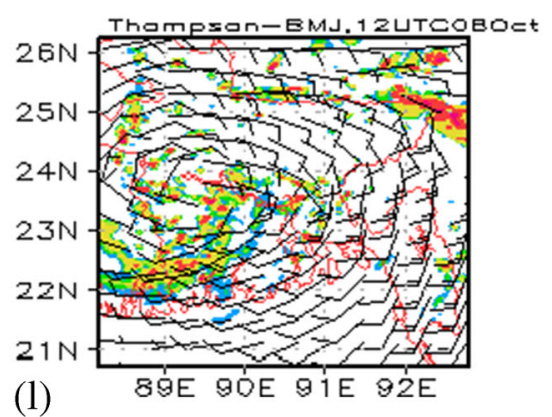

Figure 8. Same as figure 7, but for 1200 UTC of 8 October 2007.

maximum area averaged vorticity from 950-750 $\mathrm{hPa}$ and minimum area average vorticity from 500 $200 \mathrm{hPa}$ on 7 and 8 October 2007. Except for Kessler-KF, WSM3-KF simulated minimum area averaged vorticity from $950-200 \mathrm{hPa}$ and Lin-KF simulated maximum area averaged vorticity from 950-300 hPa level on 7 and 8 October. WSM6-KF simulated less area averaged vorticity than Lin-KF and more than Thompson-KF from 950-300 hPa level on 7 and 8 October. Lin-BMJ simulated maximum area averaged vorticity from $950-550 \mathrm{hPa}$ and WSM3-BMJ simulated minimum area averaged vorticity from 950-200 hPa level on 7 and 8 October. WSM6-BMJ simulated less area averaged vorticity than Lin-BMJ and more than FerrierBMJ from $950-350 \mathrm{hPa}$ level on 7 and 8 October. The negative area averaged vorticity was simulated by all MP schemes in combination with $\mathrm{CP}$ schemes from 300-100 hPa levels on both the days. The maximum area averaged vorticity was simulated by Lin-KF combination and then WSM6$\mathrm{KF}$ combination at $700-300 \mathrm{hPa}$ level on both the days. The maximum rain has also been simulated by these combinations. The simulated rainfalls are related to the vorticity at these levels.

Along the line of maximum updraft, vorticity (contour, $\times 10^{-5} / \mathrm{s}$ ) has been simulated by different MP schemes coupling with KF and BMJ schemes 

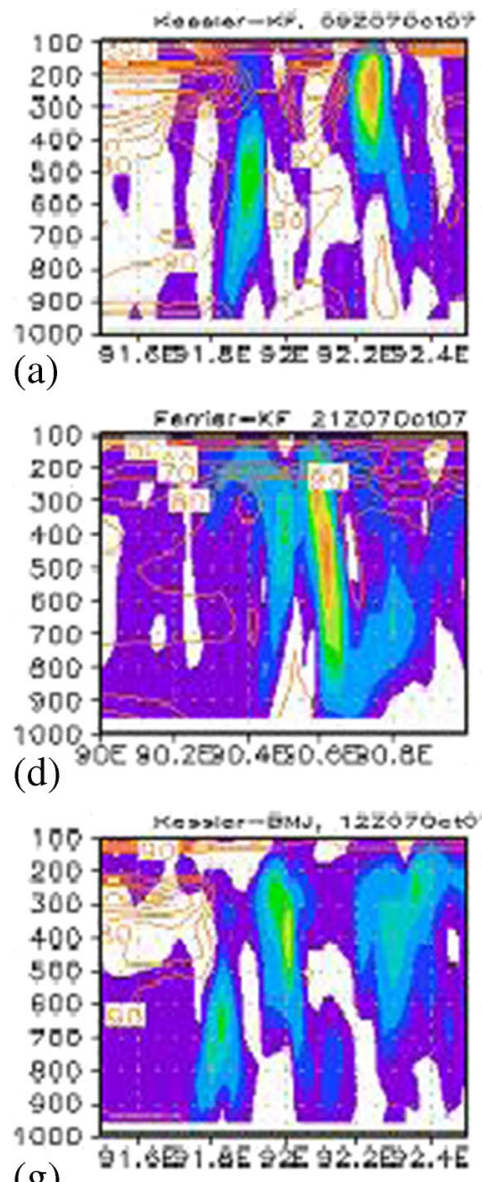

(g)

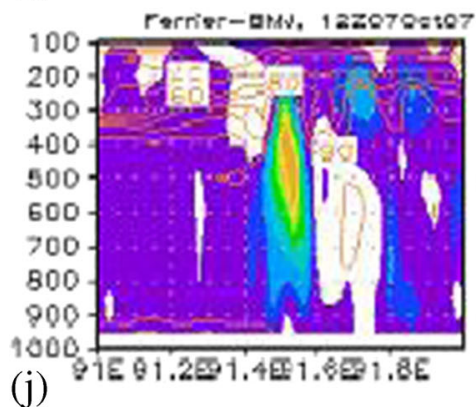

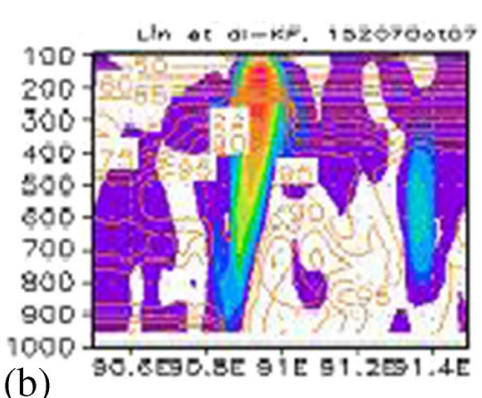

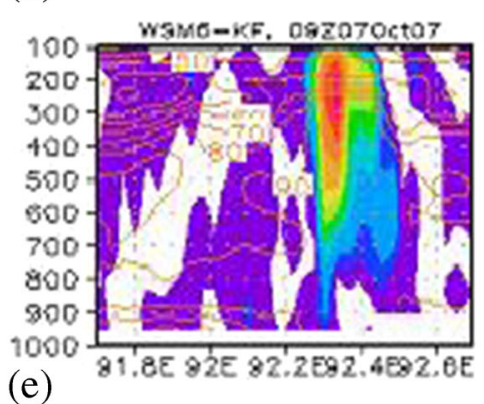

(e)
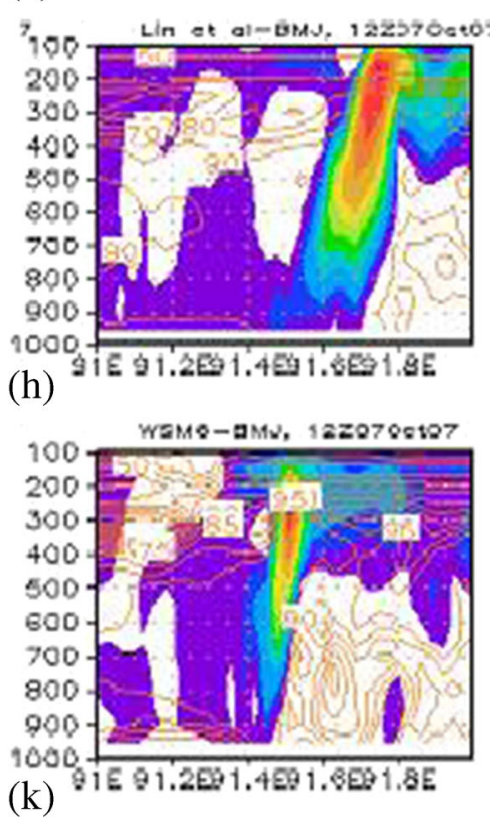

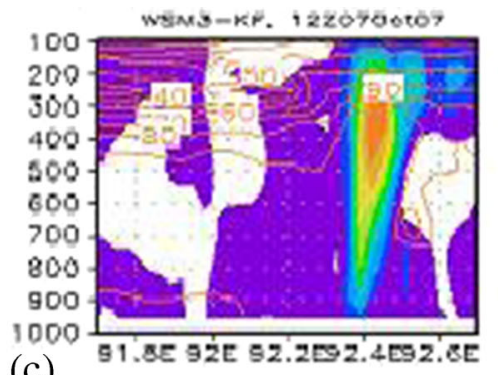

(c)
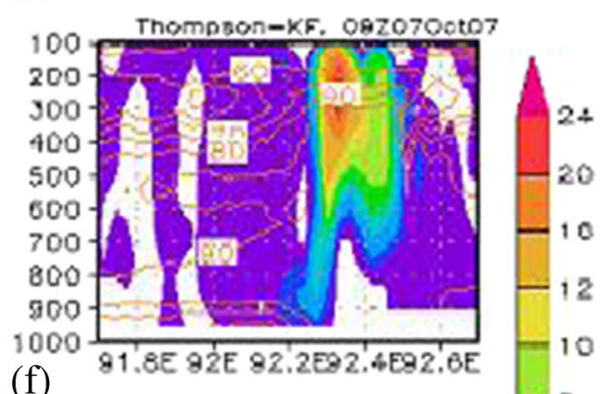

(f)
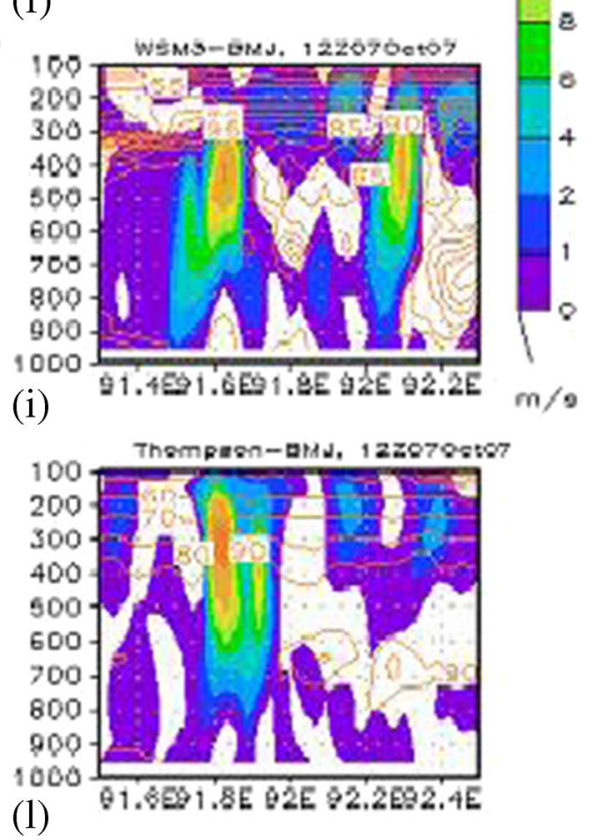

Figure 9. Simulated maximum vertical velocity (shaded) and relative humidity (contour) at Domain D2 of 7 October 2007 using Kessler, Lin et al., WSM3, Ferrier, WSM6 and Thomson schemes coupling with (a-f) KF and (g-l) BMJ schemes of heavy rainfall event.

on 7 and 8 October 2007 and is presented in figures 11 and 12. Lin-KF combination simulated negative vorticity from $950-550,950-300 \mathrm{hPa}$ and significant positive vorticity above these levels on 7 and 8 October, respectively in the regions where reflectivity and vertical velocity were maximum. Thompson-KF and Thompson-BMJ also simulated negative vorticity from 950-100 and 950-300 hPa level respectively on 8 October 2007 where the reflectivities were maximum. In all other combinations on 7 and 8 October the significant positive vorticity simulated from $950-200 \mathrm{hPa}$ levels over the regions where reflectivity and vertical velocity were maximum and positive vorticity almost surrounded by the negative vorticity in the region of maximum reflectivity and vertical velocity. The reason is that change of sign of the radial vorticity gradient is dynamically important for this instability (Itano and Ishikawa 2002). Although the area average maximum vorticity was found to be $6 \times 10^{-5} / \mathrm{s}$, the maximum and minimum vorticity along the line of maximum vertical velocity simulated by Thompson-KF were $368.14 \times 10^{-5} / \mathrm{s}$ and $-392.83 \times 10^{-5} / \mathrm{s}$ at $700 \mathrm{hPa}$. The maximum and 

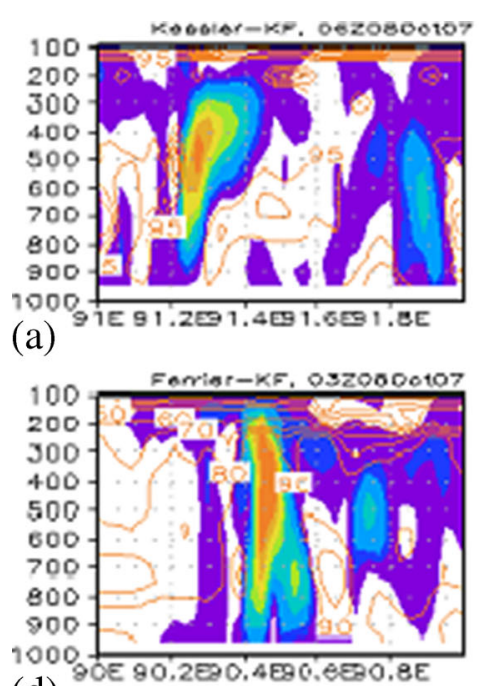

(d)

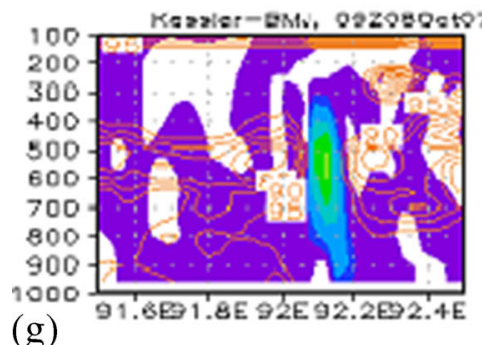

(g)

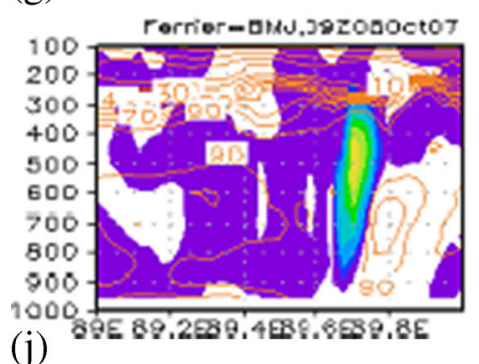

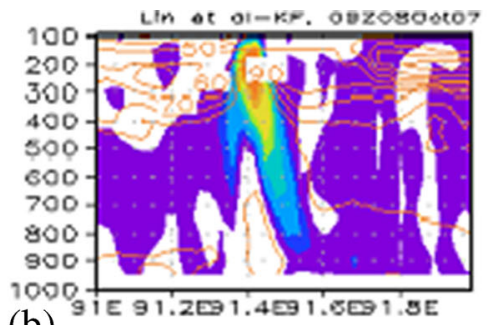

(b)

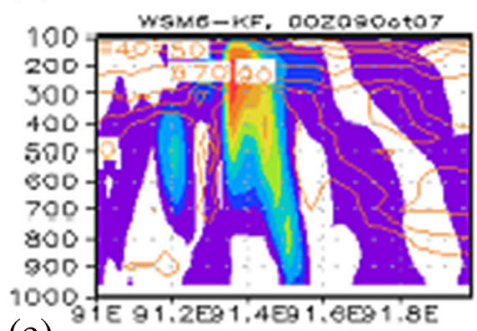

(e)

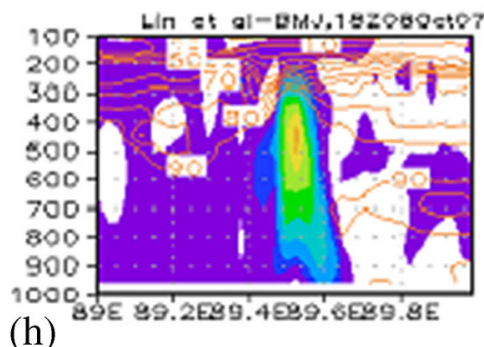

(h)

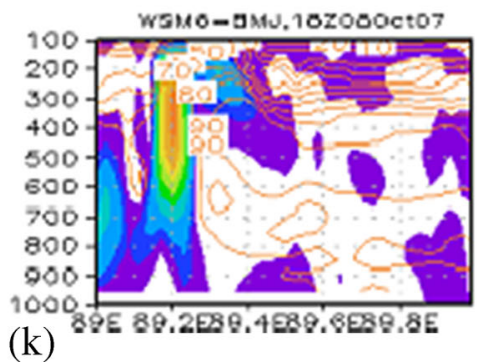

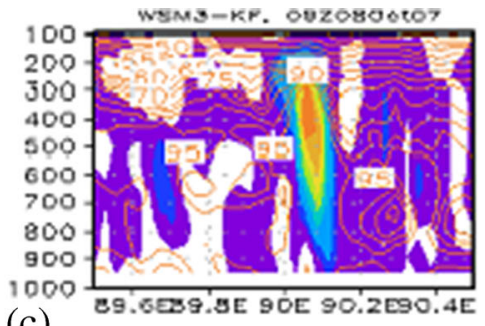

(c)

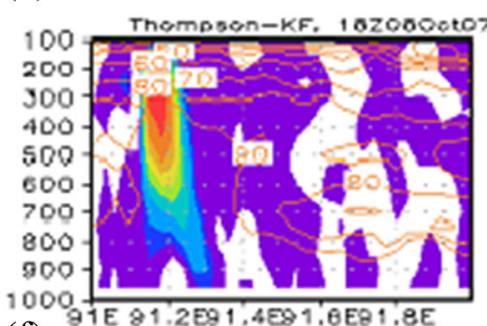

(f)

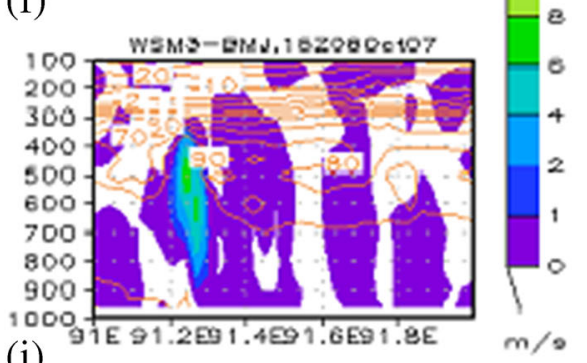

(i)

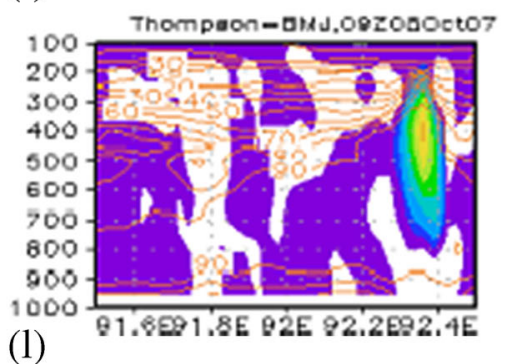

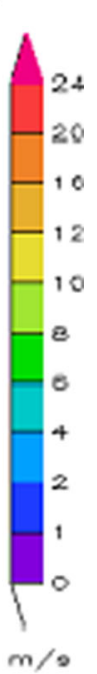

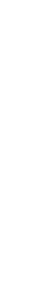

Figure 10. Same as figure 9, but for 8 October 2007.

minimum vorticity simulated along the line of maximum vertical velocity by Lin-KF were $346.62 \times$ $10^{-5} / \mathrm{s}$ and $-295.35 \times 10^{-5} / \mathrm{s}$ at 200 and $800 \mathrm{hPa}$, and by WSM6-KF are $346.54 \times 10^{-5} / \mathrm{s}$ and -338.9 $\times 10^{-5} / \mathrm{s}$ at 550 and $700 \mathrm{hPa}$, respectively.

\subsection{Rain water mixing ratio}

The rain water mixing ratio (contour, g/ kg) along the line of maximum vertical velocity using six different MPs coupling with KF and BMJ schemes on 7 and 8 October 2007 are presented in figures 14 and 15. Kessler-KF and Kessler-BMJ simulated rain water mixing ratio up to 150 and $200 \mathrm{hPa}$, respectively on 7 October. WSM3 scheme in combination with $\mathrm{KF}$ and BMJ schemes simulated rain water mixing ratio up to $100 \mathrm{hPa}$ and the maximum value was simulated at $300-200 \mathrm{hPa}$ level on 7 October. All other MPs coupling with KF and
BMJ schemes simulated rain water mixing ratio up to $500 \mathrm{hPa}$ level on 7 and 8 October.

From figures 14 and 15 it can be observed that the rain water mixing ratio is maximum at the position where the vertical velocity and reflectivity are also maximum. The maximum rain water mixing ratios were simulated by Kessler-KF at 350 $\mathrm{hPa} 10.6 \mathrm{~g} / \mathrm{kg}$, WSM3-KF at $200 \mathrm{hPa} 10.53 \mathrm{~g} / \mathrm{kg}$, WSM3-BMJ at $250 \mathrm{hPa} 11.02 \mathrm{~g} / \mathrm{kg}$, and Lin-BMJ at $600 \mathrm{hPa} 10.39 \mathrm{~g} / \mathrm{kg}$.

Area and time averaged vertical profiles of rain water mixing ratio on 7 and 8 October in combination with different MP and CP schemes are shown in figure $16(\mathrm{a}-\mathrm{d})$. The patterns of rain water profile are similar up to $550 \mathrm{hPa}$ level with all MP coupling with KF and BMJ schemes. Lin-KF and WSM6$\mathrm{KF}$ simulated maximum area averaged rain water mixing ratio from $950-600 \mathrm{hPa}$ level and 950-700 hPa level on 7 and 8 October, respectively. WSM3$\mathrm{KF}$ and Thompson-KF simulated almost same but 


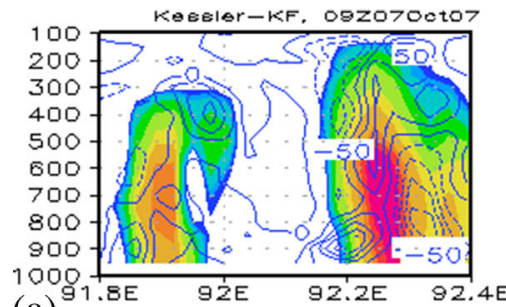

(a)

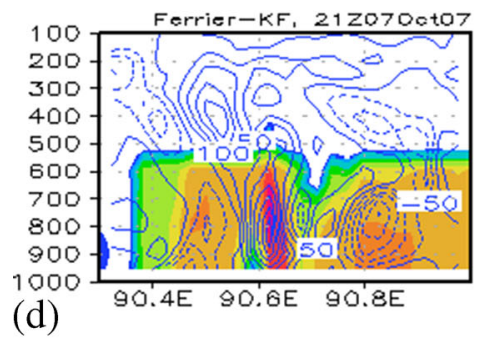

Kessler-EMd, $1270700+07$

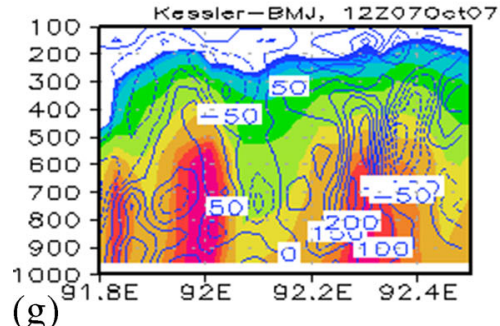

(g)

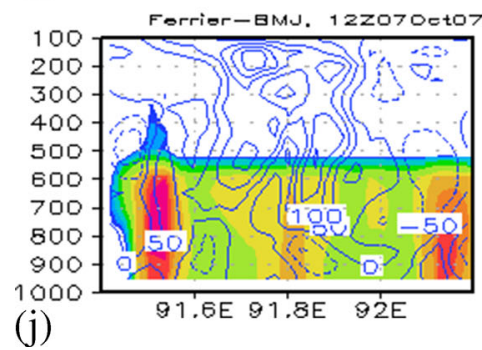

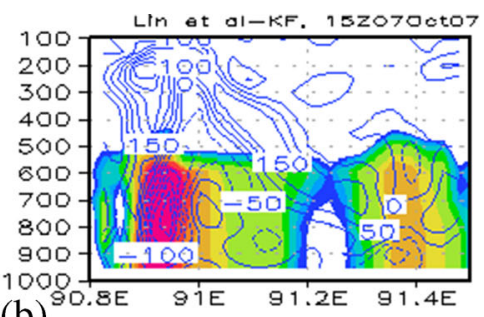

(b)

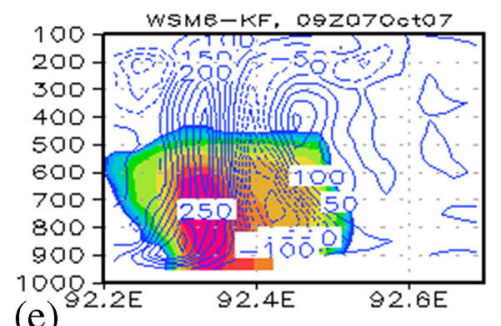

(e)

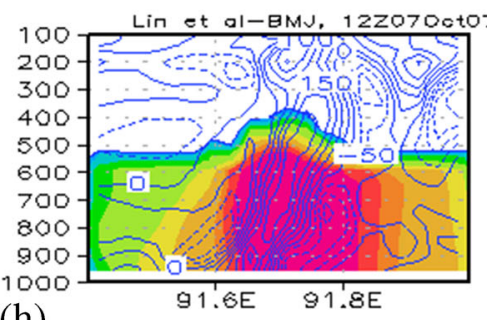

(h)

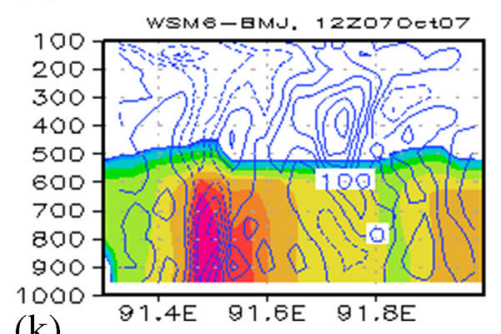

(k)

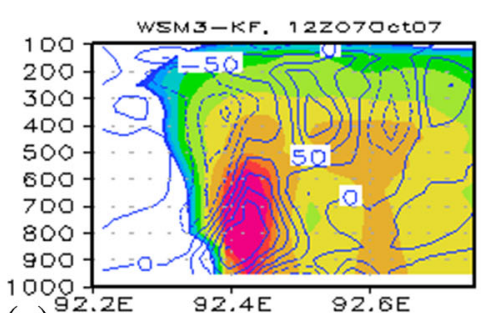

(c)

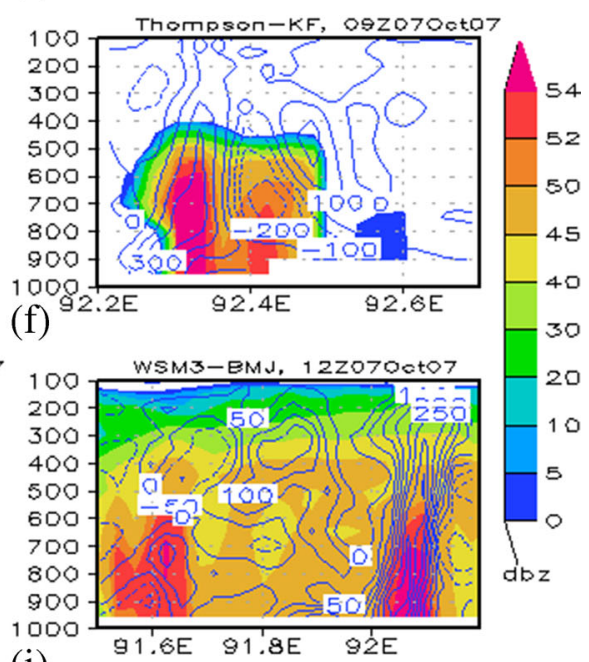

(i)

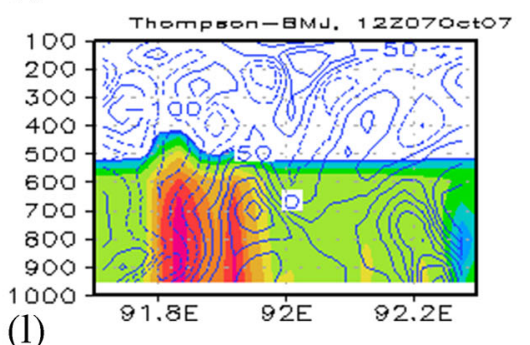

(1)

Figure 11. Same as figure 9, but for reflectivity (shaded) and vorticity (contour, $\times 10^{-5} / \mathrm{s}$ ) along the line of maximum vertical velocity of 7 October 2007.

minimum area averaged rain water mixing ratio from 950-650 hPa. WSM6-KF simulated less area averaged rain water mixing ratio than Lin-KF and more than Ferrier-KF from $950-600 \mathrm{hPa}$ level on 7 October. Kessler-KF simulated less area averaged rain water mixing ratio than Lin-KF from 950-600 hPa level on 7 and 8 October. Lin-BMJ simulated maximum area averaged rain water mixing ratio and Thompson-BMJ simulated minimum area averaged rain water mixing ratio from 950-600 hPa level on 7 and 8 October. WSM6-BMJ simulated less area averaged rain water mixing ratio than Lin-BMJ and more than Ferrier-BMJ from 950-600 hPa level on 7 and 8 October. KesslerBMJ simulated less area averaged rain water mixing ratio than Ferrier-BMJ from 950-600 hPa level on 7 and 8 October. The simulated rainfalls are related to the rain water mixing ratio below 500 $\mathrm{hPa}$ levels.

The WSM3 and Kessler schemes coupling with $\mathrm{KF}$ and BMJ schemes have simulated significant amount of rain water mixing ratio between 500 and $100 \mathrm{hPa}$, but WSM3 has simulated much more rain water mixing ratio than that of Kessler scheme. The KF and BMJ schemes coupling with WSM3 scheme simulated area averaged maximum rain water mixing ratio 0.265 and $0.227 \mathrm{~g} / \mathrm{kg}$ at $450 \mathrm{hPa}$ level on 7 October 2007. The production of rain water mixing ratio depends on MP schemes as well as CP schemes.

\subsection{Cloud water mixing ratio}

The cloud water mixing ratio (shaded, $\mathrm{g} / \mathrm{kg}$ ) along the line of maximum vertical velocity using different MPs coupling with KF and BMJ schemes on 7 and 8 October 2007 are presented in figures 14 and 15. Kessler and WSM3 MPs in combination of $\mathrm{KF}$ and BMJ schemes simulated cloud water mixing ratio up to $100 \mathrm{hPa}$ on 7 and 8 October. All other MPs coupling with KF and BMJ schemes simulated cloud water mixing ratio up to $300 \mathrm{hPa}$ 


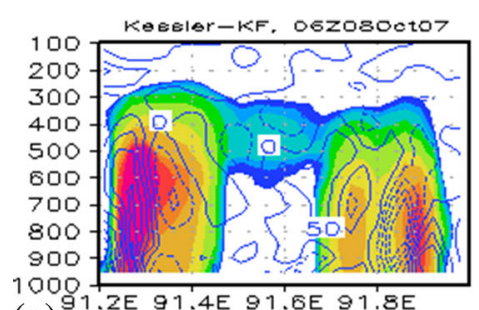

(a)

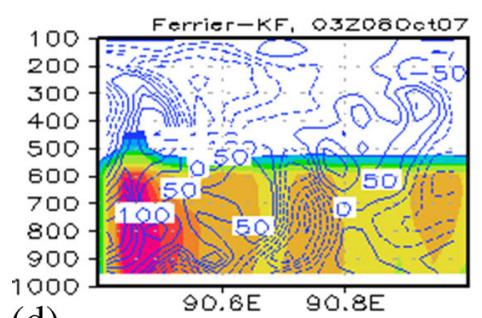

(d)

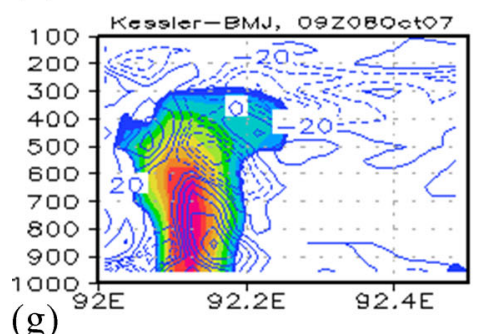

(g)

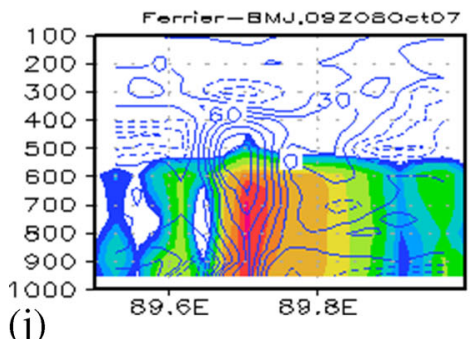

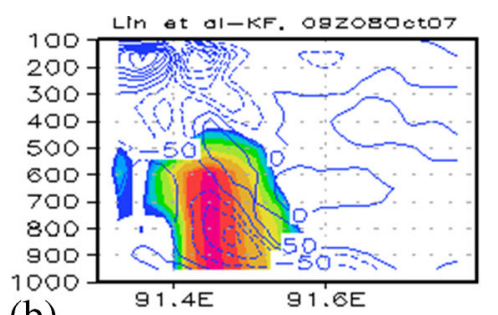

(b)

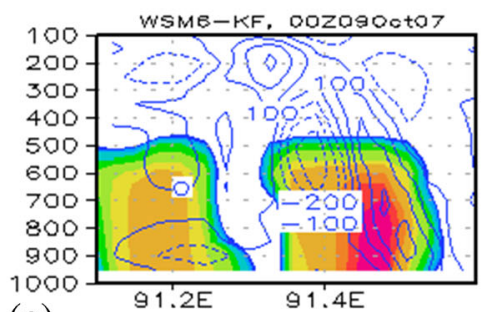

(e)

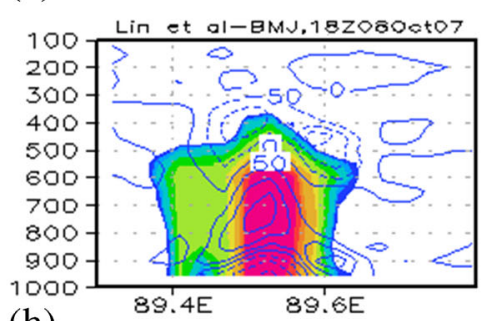

(h)

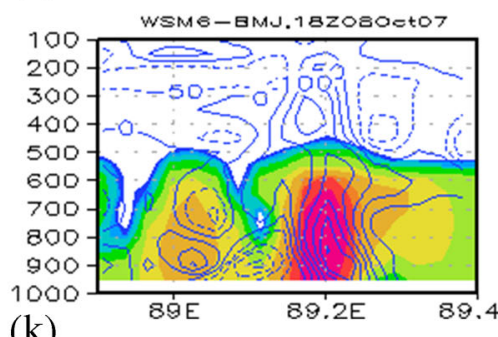

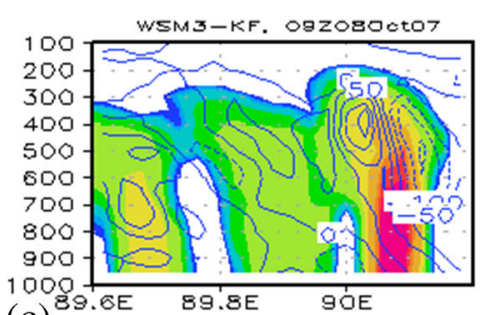

(c)

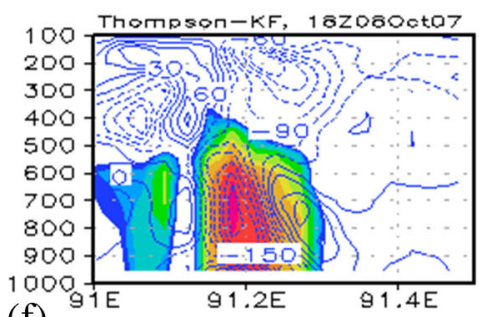

(f)

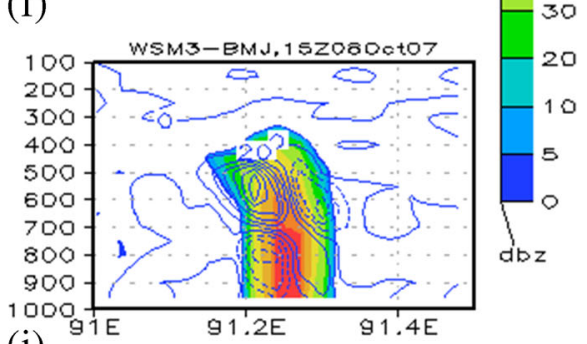

(i)

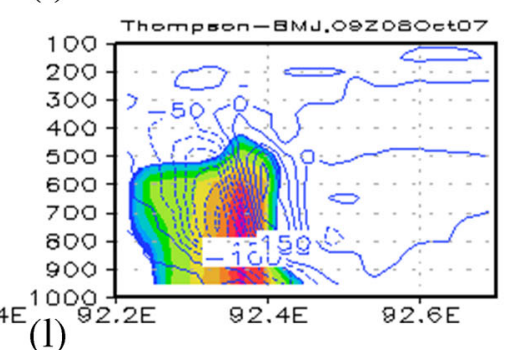

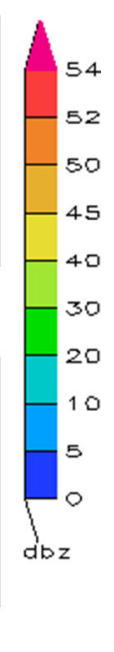

54

52

0

\section{5} . (l)

Figure 12. Same as figure 11, but for 8 October 2007.

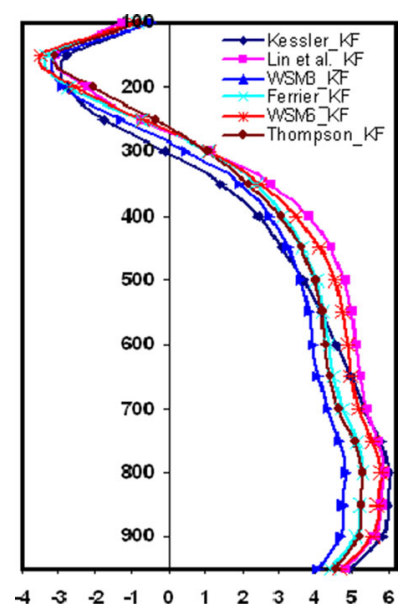

(a)

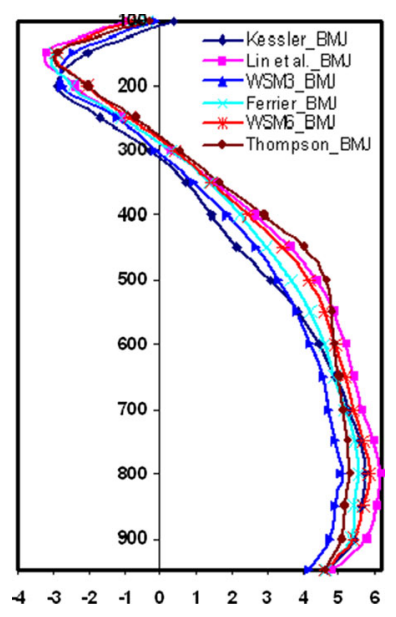

(b)

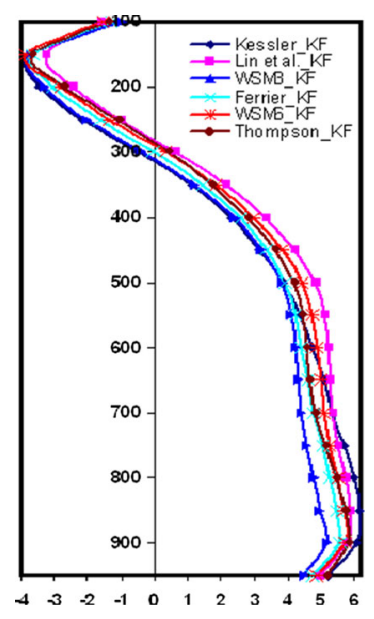

(c)

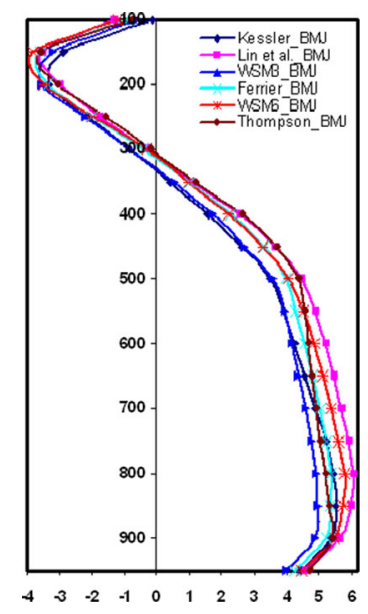

(d)

Figure 13. Vertical profiles of time and space averaged vorticity $\left(\times 10^{-5} / \mathrm{s}\right)$ simulated by Kessler, Lin et al., WSM3, Ferrier, WSM6 and Thomson schemes coupling with KF and BMJ schemes (a and b) of 7 and (c and d) 8 October 2007, respectively. 

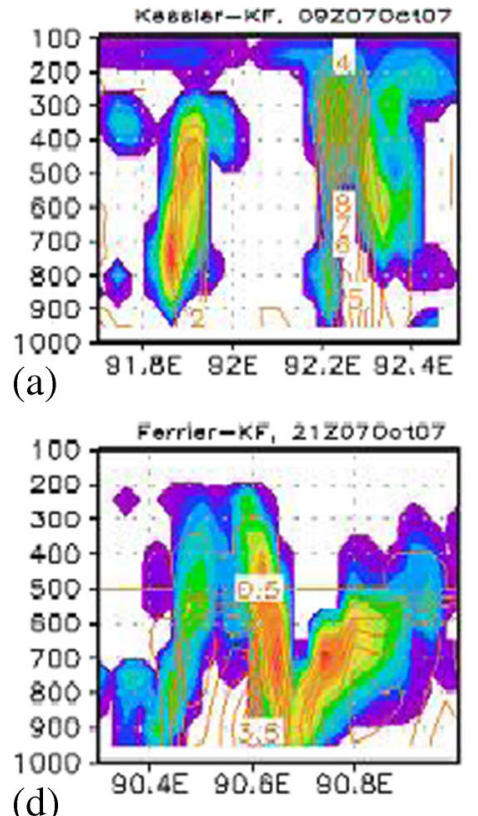

(d)
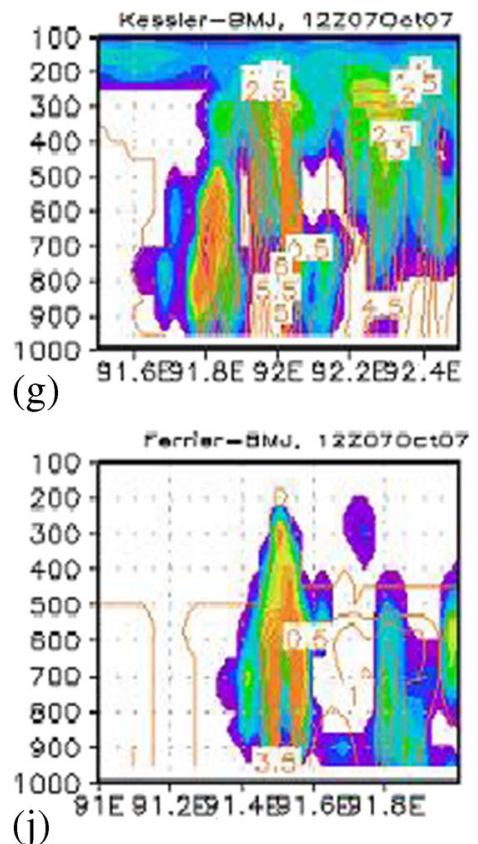

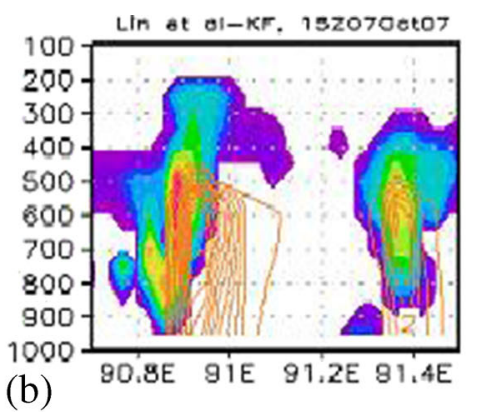

(b)

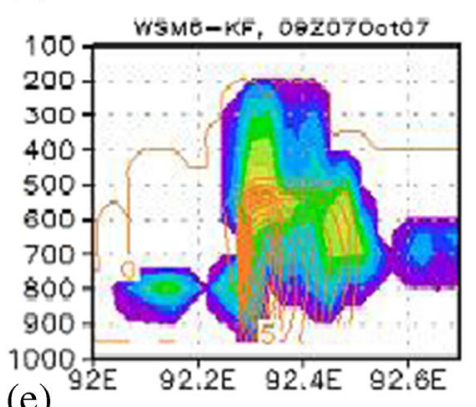

(e)
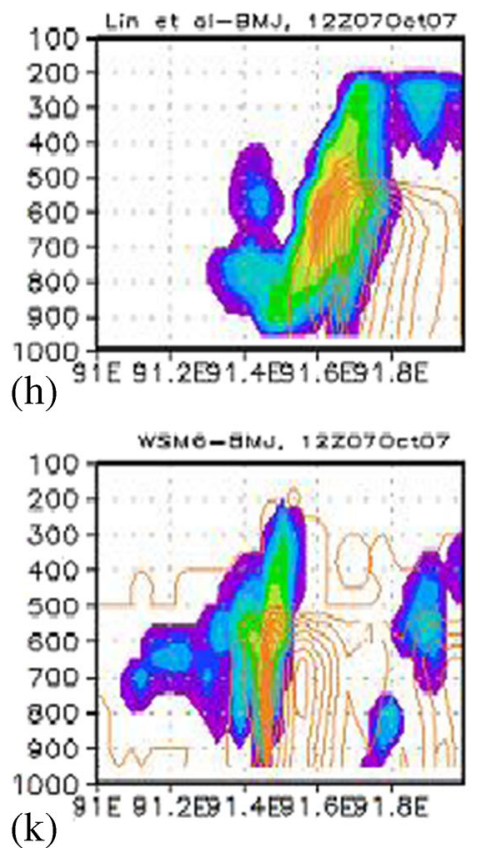

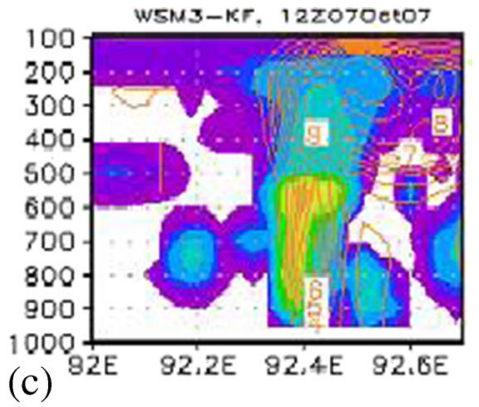

(c)

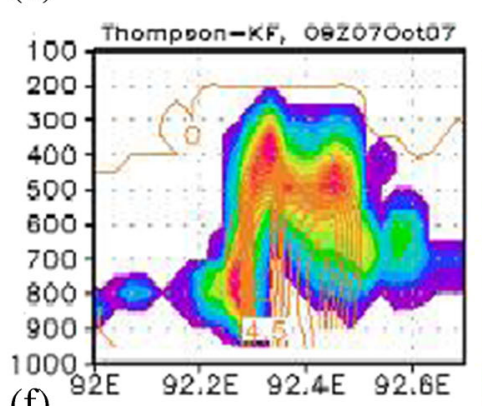

(f)

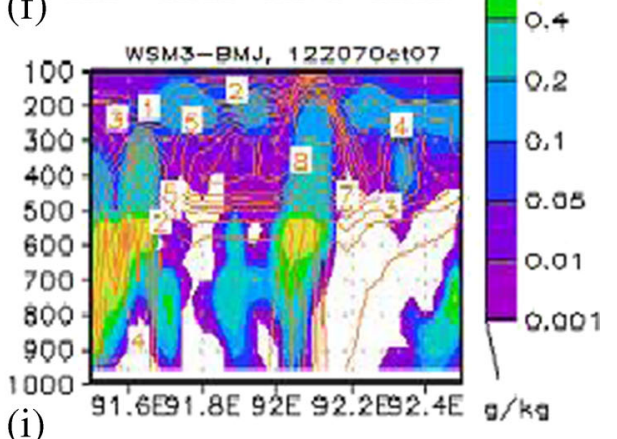

(i)

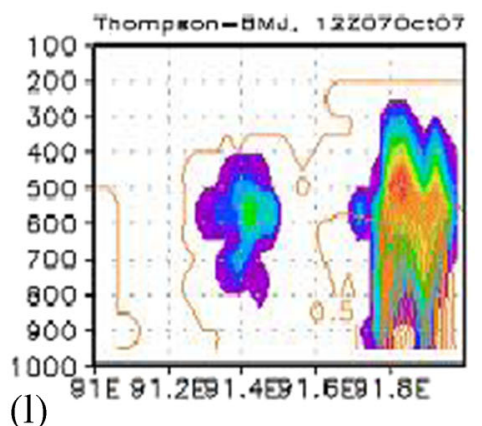

Figure 14. Same as figure 9, but for cloud water mixing ratio (shaded) and rain water mixing ratio (contour) along the line of maximum vertical velocity of 7 October 2007.

level. The cloud water mixing ratio is found to be maximum along the vertical line where the vertical velocity and reflectivity are also maximum. The maximum cloud water mixing ratio were simulated by Thompson-KF at $750 \mathrm{hPa} 2.33 \mathrm{~g} / \mathrm{kg}$, Lin-KF at $600 \mathrm{hPa} 1.91 \mathrm{~g} / \mathrm{kg}$, Kessler-BMJ at $700 \mathrm{hPa} 2.07$ $\mathrm{g} / \mathrm{kg}$, and Thompson-BMJ at $500 \mathrm{hPa} 1.89 \mathrm{~g} / \mathrm{kg}$.

Area and time averaged vertical profiles of cloud water mixing ratio on 7 and 8 October in combination of different MP and $\mathrm{CP}$ schemes are shown in figure $17(\mathrm{a}-\mathrm{d})$. The pattern of cloud water mixing ratio profile is similar up to $500 \mathrm{hPa}$ level with all $\mathrm{MP}$ schemes coupling with KF and BMJ schemes on 7 and 8 October 2007. The Kessler and WSM3 schemes simulated cloud water mixing ratio up to $100 \mathrm{hPa}$ and other MP schemes simulated up to $350 \mathrm{hPa}$ level. All of the six MP schemes simulated two maxima at 750 and $500 \mathrm{hPa}$ coupling with $\mathrm{KF}$ and BMJ schemes on 7 and 8 October 2007. The Kessler and WSM3 schemes simulated third maximum at 200 and $250 \mathrm{hPa}$ level coupling with KF scheme, and 200 and $400 \mathrm{hPa}$ level coupling with BMJ scheme. The upper tropospheric cloud water maximum as simulated by Kessler scheme is approximately five times greater than that of WSM3 


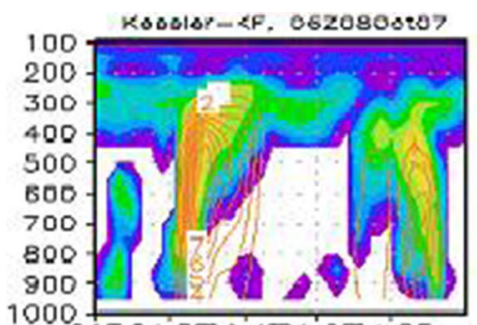

(a) $91 \mathrm{E} 91.2 \mathrm{G1.461.6 \textrm {BS }} .8 \mathrm{E}$

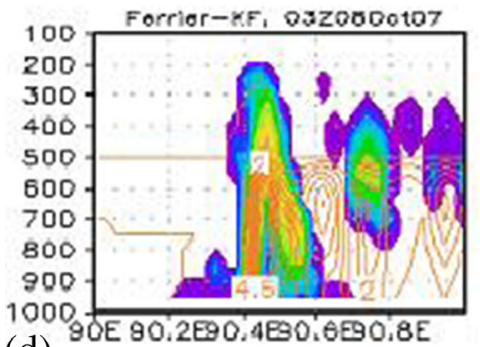

(d)

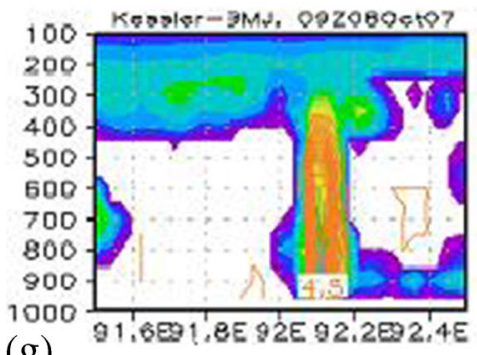

(g)

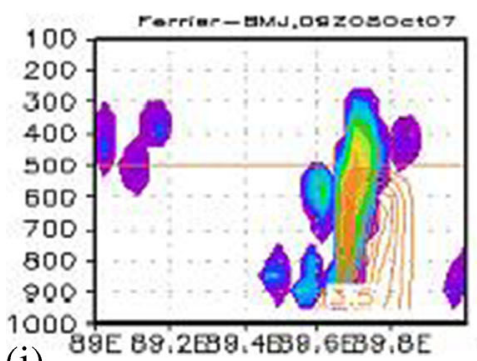

(j)

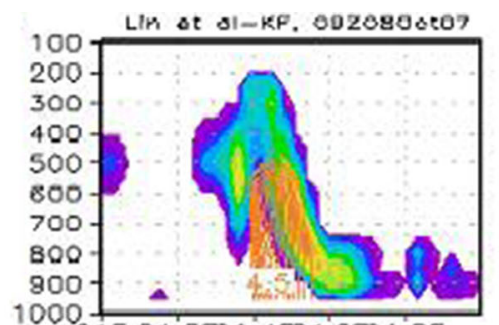

(b)

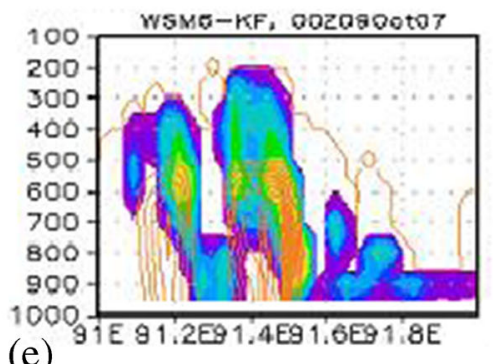

(e)
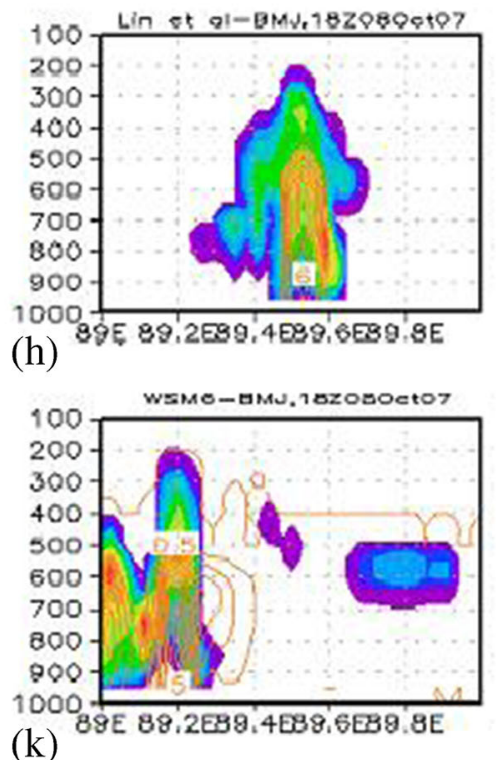

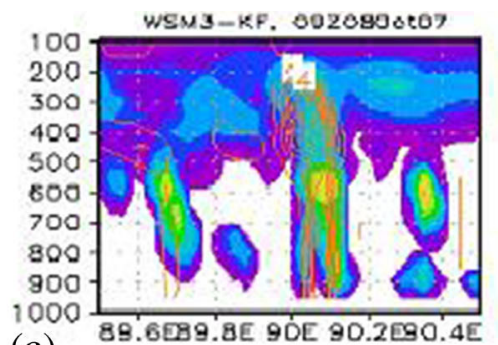

(c)

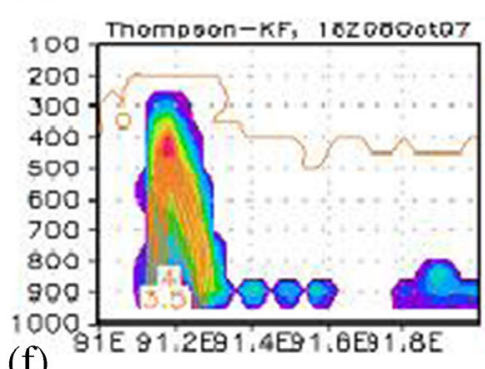

(f)
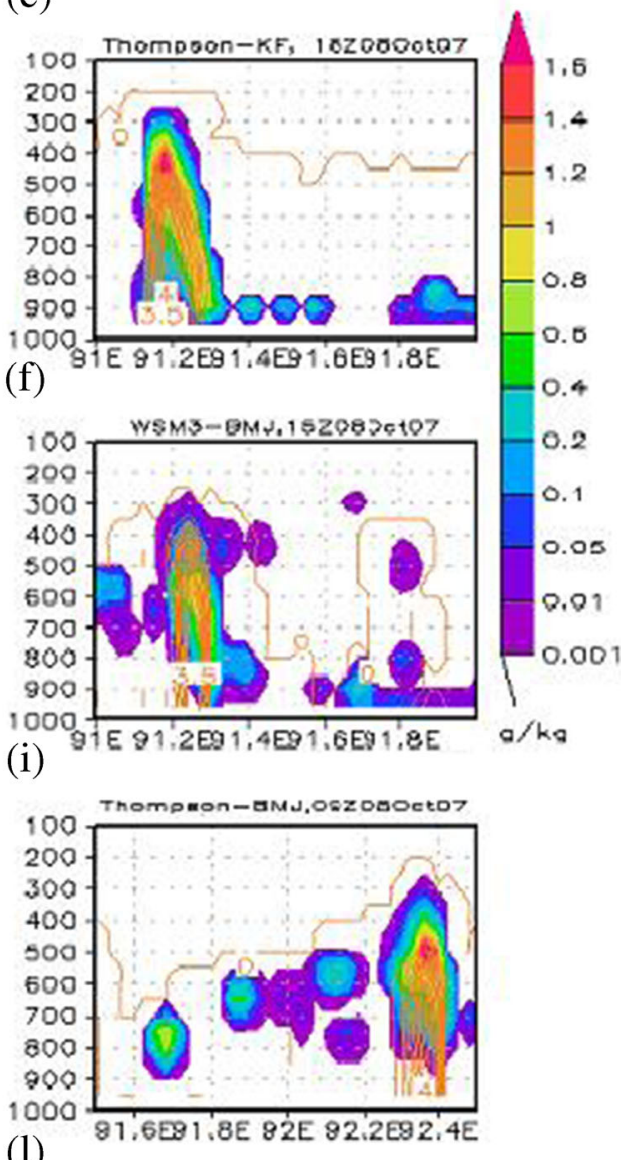

(1)

Figure 15. Same as figure 14, but for 8 October 2007.

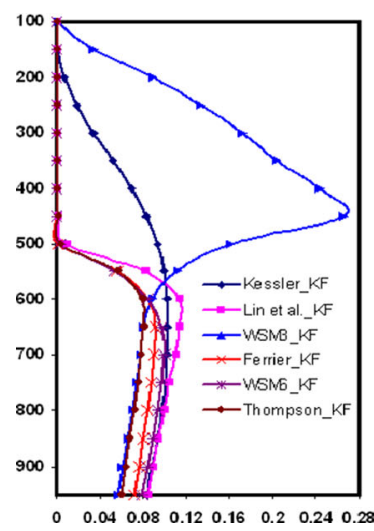

(a)

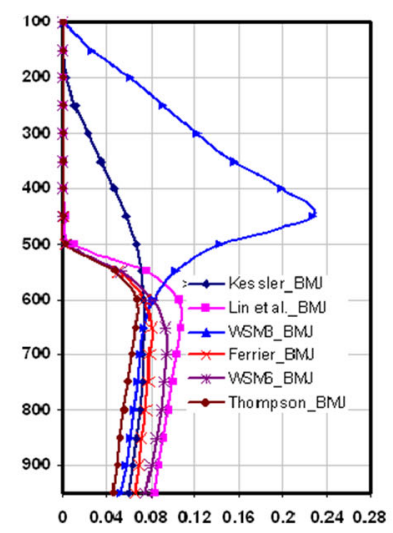

(b)

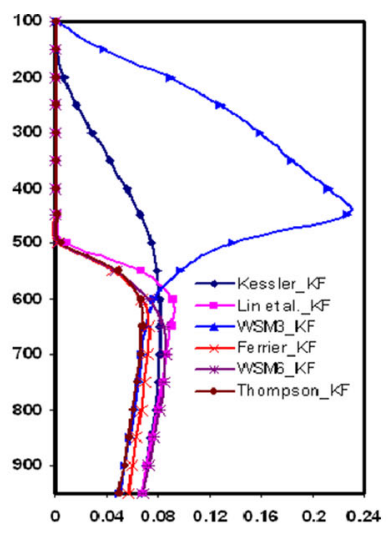

(c)

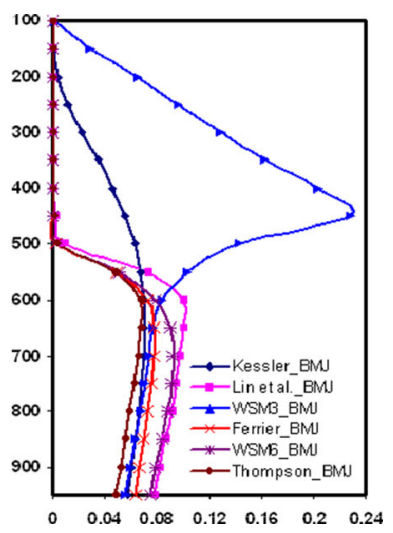

(d)

Figure 16. Same as figure 13, but for rain water mixing ratio $\left(\mathrm{g} \mathrm{kg}^{-1}\right)$. 


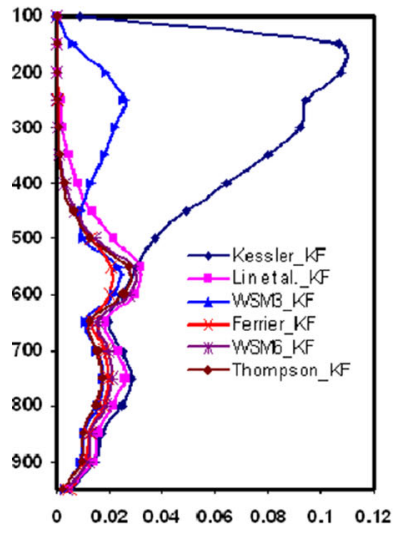

(a)

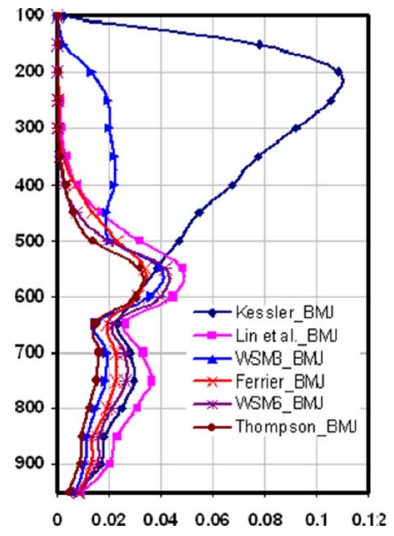

(b)

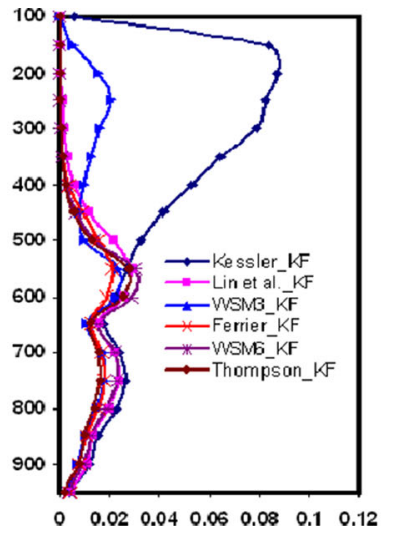

(c)

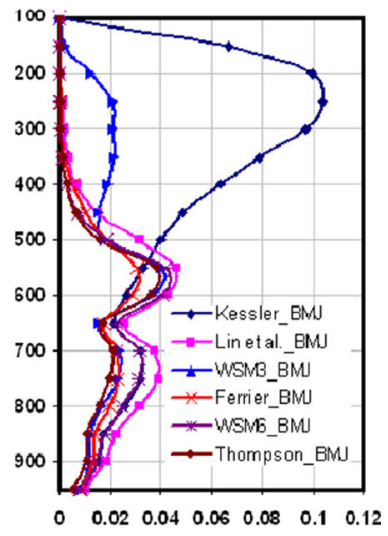

(d)

Figure 17. Same as figure 13 , but for cloud water mixing ratio $\left(\mathrm{g} \mathrm{kg}^{-1}\right)$.

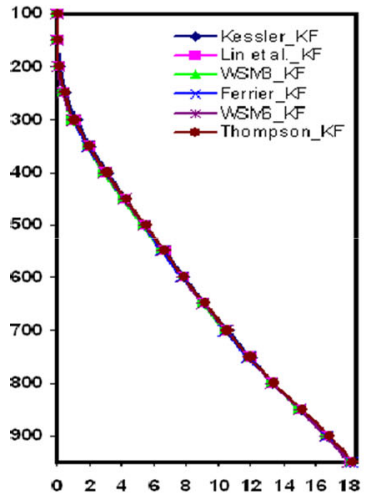

(a)

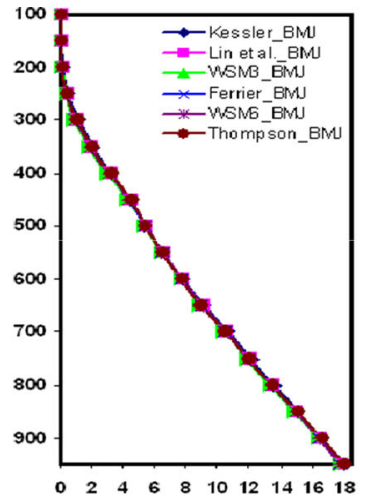

(b)

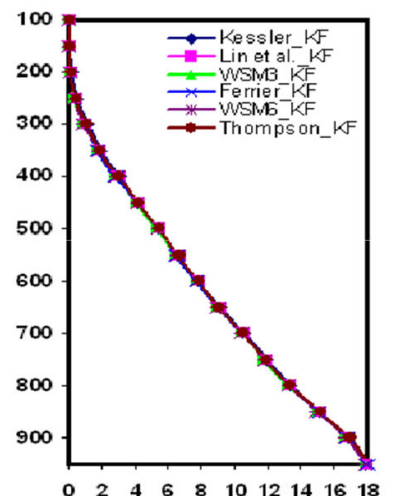

(c)

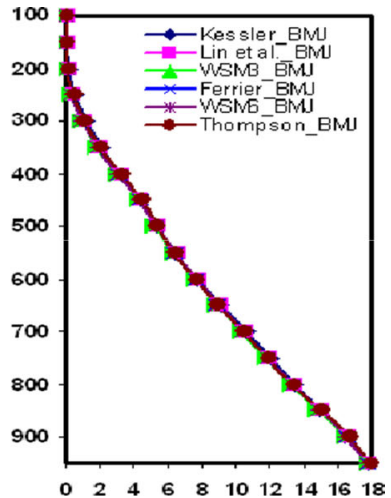

(d)

Figure 18. Same as figure 13, but for water vapour mixing ratio $\left(\mathrm{g} \mathrm{kg}^{-1}\right)$.

scheme. WSM3-KF and Thompson-KF simulated minimum area averaged and cloud water mixing ratio and Kessler-KF simulated maximum area averaged cloud water mixing ratio from 950-650 hPa level on 7 and 8 October 2007. Lin-KF simulated less area averaged cloud water mixing ratio than Kessler-KF and greater than WSM6-KF. Lin-BMJ simulated maximum and ThompsonBMJ simulated minimum area averaged cloud water mixing ratio from $950-650 \mathrm{hPa}$ level on 7 and 8 October 2007. Kessler-BMJ simulated area averaged cloud water mixing ratio was less than LinBMJ and more than WSM6-BMJ combination on 7 and 8 October.

\subsection{Water vapour mixing ratio}

Area and time averaged vertical profiles of water vapour mixing ratio $(\mathrm{g} / \mathrm{kg})$ on 7 and 8 October in combination of different MP and $\mathrm{CP}$ schemes are shown in figure $18(\mathrm{a}-\mathrm{d})$. The pattern of water vapour profile is similar up to $150 \mathrm{hPa}$ level with all MPs coupling with KF and BMJ schemes. The water vapour mixing ratio simulated maximum at the surface and decreased with height for all MPs coupling with KF and BMJ schemes. The simulated water vapour mixing ratio is approximately equal for all MPs schemes with little variation. The pattern shows that the simulated water vapour mixing ratio is not dependent on the choice of MP and $\mathrm{CP}$ schemes.

\subsection{Cloud graupel mixing ratio}

Area and time averaged vertical profiles of graupel mixing ratio $(\mathrm{g} / \mathrm{kg})$ on 7 and 8 October using Lin et al., WSM6 and Thompson MPs in combination of different CP schemes are shown in figure 19(a and b). The MP schemes simulated cloud graupel mixing ratio was maximum around $500 \mathrm{hPa}$ levels. KF scheme simulated greater graupel mixing ratio than that of BMJ scheme coupling with all 


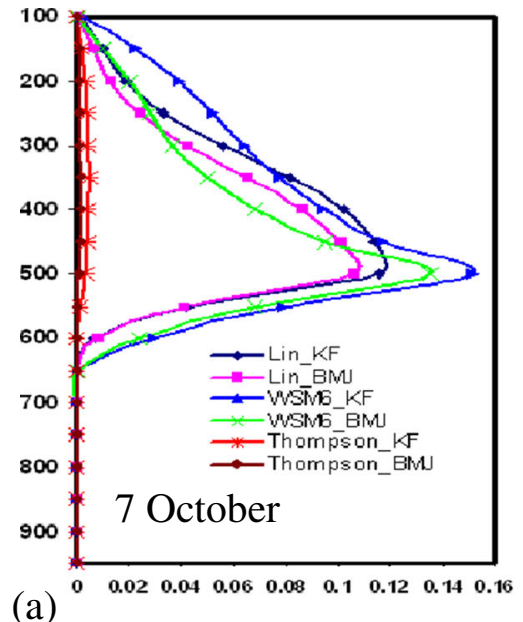

(a)

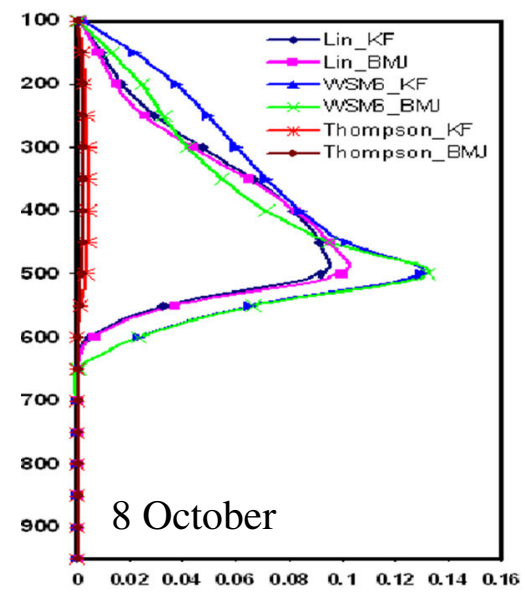

(b)
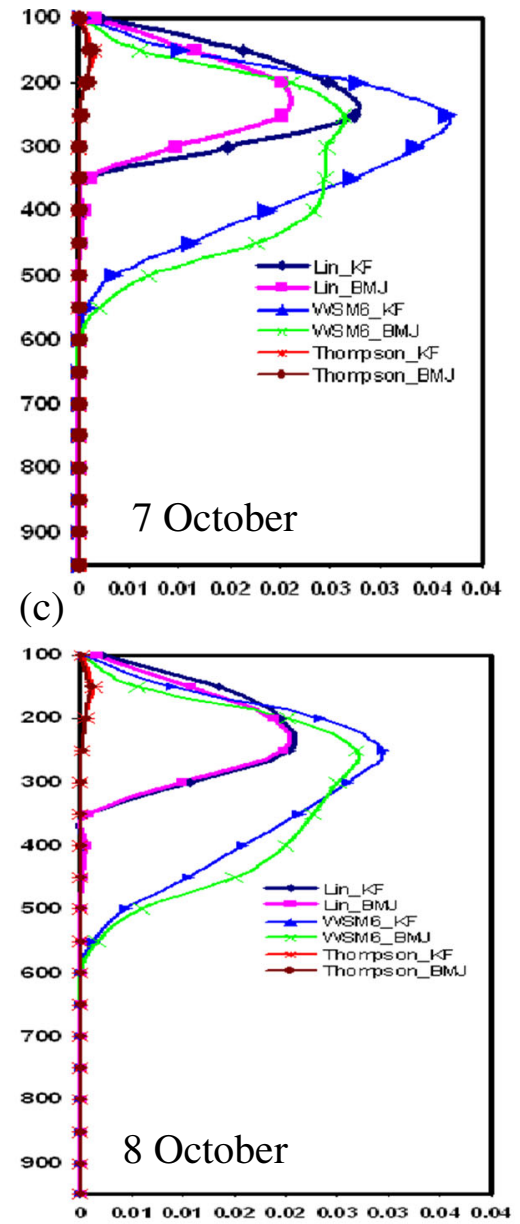

(d)
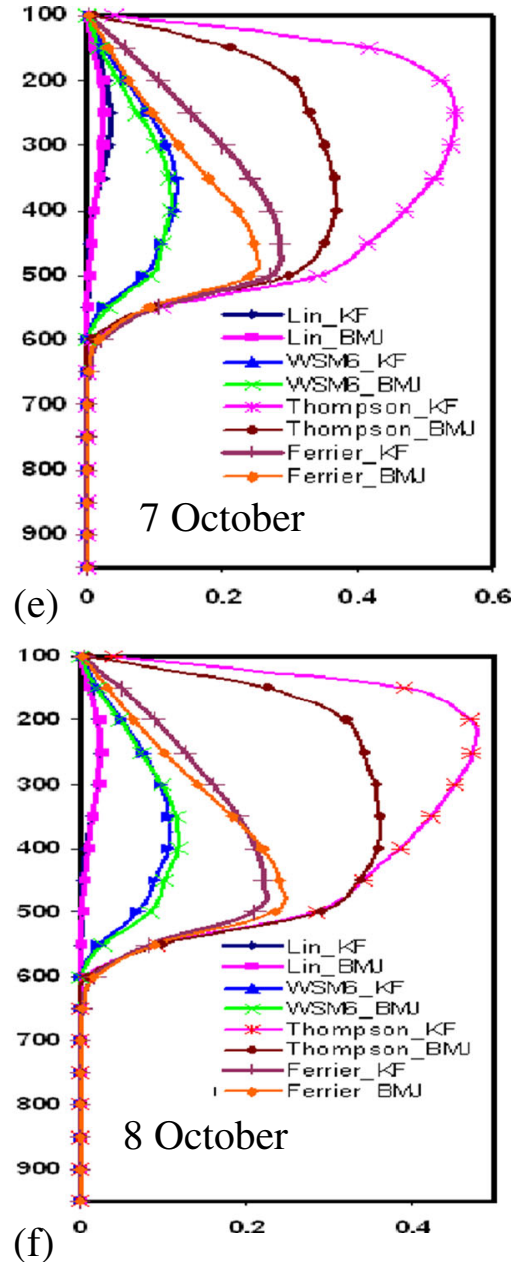

Figure 19. Vertical profile of time and space averaged (a and b) graupel mixing ratio, (c and $\mathbf{d})$ ice mixing ratio and (e and f) snow mixing ratio of 7 and 8 October 2007, respectively simulated by different MP coupling with KF and BMJ schemes.

MPs. The WSM6 scheme simulated larger cloud graupel mixing ratio and Thompson scheme simulated less cloud graupel mixing ratio than that of other schemes. The pattern was similar on 7 and 8 October 2007 for all combinations of MPs and CPs. Graupel began to be produced at $650 \mathrm{hPa}$ and sharp spikes simulated by WSM6 MP at 500 $\mathrm{hPa}$ was $0.15 \mathrm{~g} / \mathrm{kg}$ and after that it decreased to 00 at $100 \mathrm{hPa}$.

\subsection{Cloud ice mixing ratio}

Area and time averaged vertical profiles of ice mixing ratio $(\mathrm{g} / \mathrm{kg})$ on 7 and 8 October using Lin et al., WSM6 and Thompson MPs in combination of different CP schemes are shown in figure 19(c and d). Lin et al., WSM6 and Thompson MP schemes simulated cloud ice maximum around $250 \mathrm{hPa}$ level. It is evident that substantial difference exists between the various cloud ice profiles. For instance, the WSM6 profile exhibited a prominent spike containing much larger cloud ice mixing ratio values between 500 and $100 \mathrm{hPa}$ and Thompson scheme simulated less cloud ice mixing ratio. KF scheme simulated greater ice mixing ratio than that of BMJ scheme coupling with all MPs. The Thompson MP scheme in combination of KF and BMJ schemes simulated much smaller amount of graupel and ice. Lin et al. scheme simulated cloud ice between 350 and $100 \mathrm{hPa}$ levels. While the Kessler and WSM3 schemes simulated practically no cloud snow, graupel and ice and Ferrier MP Scheme simulated no cloud graupel and ice. Unfortunately, we do not have any hydrometeor data for validating these simulations of hydrometeor profiles.

\subsection{Cloud snow mixing ratio}

The area and time averaged vertical profiles of snow mixing ratio $(\mathrm{g} / \mathrm{kg})$ on 7 and 8 October using Lin et al., Ferrier, WSM6, and Thompson MPs in combination of different CP schemes are shown in figure 19(e and f). It is evident from the figure that the vertical structure and magnitude of these profiles vary greatly and $\mathrm{KF}$ simulated larger snow 
than BMJ scheme. Overall, the Thompson scheme generated the greatest amount of snow between 650 and $100 \mathrm{hPa}$. The abundance of snow in the mid troposphere (below $400 \mathrm{hPa}$ ) may be due to the enhanced ice content (figure $19 \mathrm{c}$ and $\mathrm{d}$ ) in the upper troposphere. The Ferrier scheme simulated approximately half of the snow than that of Thompson scheme, WSM6 scheme simulated approximately half of the snow than that of Ferrier scheme, and Lin scheme simulated approximately half of the snow than that of WSM6 scheme. Again WSM6 scheme in combination with BMJ scheme simulated more snow than KF scheme.

\section{Conclusions}

In the present study, 9 and $3 \mathrm{~km}$ nested domain have been used to simulate the heavy rainfall events from 7-9 October 2007 over Bangladesh. To examine the sensitivity of the simulations of six different microphysical schemes (Kessler, Lin et al., WSM3, Ferrier, WSM6 and Thompson) and two different cumulus parameterization schemes, Kain-Fritsch and Betts-Miller-Janjic were considered with 0000 UTC of 7 October 2007 initial condition. The WRF model was able to simulate many features of heavy rainfall event, but with some differences. The study showed large variations among the six microphysical schemes. The microphysical schemes had a major impact on time and location of rainfall intensity. BMJ CP coupling with all MPs failed to simulate heavy rainfall in the southern and southeastern parts of Bangladesh on 7 and 8 October. The simulated heavy rainfall position shifted towards northwest for all MP schemes coupling with KF scheme on 8 October. The simulated area average rainfall on $7\left(21^{\circ}-23.5^{\circ} \mathrm{N}\right.$ and $\left.89^{\circ}-92.5^{\circ} \mathrm{E}\right)$ and $8\left(21.5^{\circ}-25^{\circ} \mathrm{N}\right.$ and $\left.89^{\circ}-92.5^{\circ} \mathrm{E}\right)$ October were compared using Lin-KF combination. Out of all MP schemes, WSM3-KF simulated less area average rainfall coupling with $\mathrm{KF}$ scheme. The simulated wind speed showed the circulation pattern at $850 \mathrm{hPa}$ for all MP schemes coupling with $\mathrm{KF}$ and BMJ schemes. The cyclonic circulation shifted towards north-northwestward direction and rainfall pattern also shifted towards that direction, which suggests that rainfall pattern moves along with the circulation during 7-9 October 2009.

The updraft simulated was as high as $20 \mathrm{~ms}^{-1}$ in the upper troposphere by using Lin-KF, WSM3$\mathrm{KF}$, Ferrier-KF and Thompson-KF combination. The simulated updraft in domain D1 is much less than that of domain D2. The updraft simulated by Kessler-BMJ and WSM3-BMJ combination on 7 and 8 October 2007 over the region was much less than that of other combinations. The downdraft was generally weaker but was seen throughout the depth of the troposphere and maximum updraft was seen in the middle and upper troposphere. The sharp peak of relative humidity up to $300 \mathrm{hPa}$ level was simulated along the vertical line where maximum updrafts have been found for all MPs coupling with $\mathrm{KF}$ and BMJ schemes. The maximum reflectivity was simulated in the eastern and southeastern parts by six different MPs coupling with CP schemes.

A significant positive vorticity was simulated at around 950-200 hPa levels over the regions where reflectivity and vertical velocity were maximum and positive vorticity was almost surrounded by the negative vorticity in the region of maximum reflectivity and vertical velocity on 7 and 8 October. Although the area average maximum vorticity was found to be $6 \times 10^{-5} / \mathrm{s}$, the maximum and minimum vorticity along the line of maximum vertical velocity simulated by Thompson-KF were $3.6814 \times 10^{-3} / \mathrm{s}$ and $-3.9283 \times 10^{-3} / \mathrm{s}$ at $700 \mathrm{hPa}$ level. The maximum vorticity was simulated by Lin-KF then WSM6-KF combination at 700-300 $\mathrm{hPa}$ level and also maximum rain was simulated by these combinations. Vorticity at these levels were related to the rainfall.

The simulated rain water and cloud water mixing ratio were maximum at the position where the vertical velocity and reflectivity also maximum. The production of rain water mixing ratio depends on MP schemes as well as CP schemes. Rainfall depends on rain water mixing ratio between 950 and $500 \mathrm{hPa}$ level. Rain water mixing ratio above $500 \mathrm{hPa}$ level had no effect on surface rain. The water vapour mixing ratio is independent of $\mathrm{MPs}$ and $\mathrm{CP}$ schemes. KF scheme simulated larger graupel, ice and snow mixing ratio than BMJ scheme. The Lin-KF combination gave the most excellent performance and WSM6-KF combination gave the second best results as compared to the performance of all other combinations.

\section{Acknowledgements}

The author is grateful to the Director of SMRC, Mrs. Arjumand Habib for providing an opportunity to take up this program at the centre. The author acknowledges Mesoscale and Microscale Meteorology Division of NCAR for providing WRF-ARW modelling system for the present study. The author is grateful to National Centre for Atmospheric Research (NCAR), USA for making the WRF (WRF-ARW) model available to modelling community. The Grid Analysis and Display System software (GrADS) was used for analytical purposes and displaying figures. 


\section{References}

Dudhia J 1989 Numerical study of convection observed during the Winter Monsoon Experiment using a mesoscale two dimensional model; J. Atmos. Sci. 46 3077-3107.

Dudhia J, Hong S Y and Lim K S 2008 A new method for representing mixed-phase particle fall speeds in bulk microphysics parameterizations; J. Meteor. Soc. Japan 86A $33-44$.

Ek M B, Mitchell K E, Lin Y, Rogers E, Grunmann P, Koren V, Gayno G and Tarpley J D 2003 Implementation of Noah land surface model advances in the National Centers for Environmental Prediction operational mesoscale Eta Model; J. Geophys. Res. 108 8851, doi: 10.1029/2002JD003296.

Etherton B and Santos P 2008 Sensitivity of WRF forecasts for south Florida to initial conditions; Wea. Forecast 23 725-740.

Ferrier B S, Tao W K and Simpson J 1995 A double moment multiple phase four-class bulk ice scheme. Part II: Simulations of convective storms in different largescale environments and comparisons with other bulk parameterizations; J. Atmos. Sci. 52 1001-1033.

Hong S Y and Pan H L 1996 Nonlocal boundary layer vertical diffusion in a medium-range forecast model; Mon. Weather Rev. 124 2322-2339.

Hong S Y, Dudhia J and Chen S H 2004 A revised approach to ice microphysical processes for the bulk parameterization of clouds and precipitation; Mon. Weather Rev. 132 103-120.

Hong S Y and Lim J 2006 The WRF Single-Moment 6-Class Microphysics Scheme (WSM6); J. Korean Meteor. Soc. 42 129-151.

Hong Y S, Noh J Y and Dudhia J 2006 A new vertical diffusion package with an explicit treatment of entrainment process; Mon. Weather Rev. 134 2318-2341.

Itano T and Ishikawa H 2002 Effect of negative vorticity on the formation of multiple structure of natural vortices; J. Atmos. Sci. 59 3254-3262.

Janjic Z I 1994 The step-mountain eta coordinate model: Further developments of the convection, viscous sublayer, and turbulence closure schemes; Mon. Weather Rev 122 927-945.

Janjic Z I 2000 Comments on developments and evaluation of a convection scheme for use in climate models; J. Atmos. Sci. $\mathbf{5 7} 3686$.

Kain J S 2004 The Kain-Fritsch convective parameterization: An update; J. Appl. Meteor. 43 170-181.

Kain J S and Fritsch J M 1990 A one-dimensional entraining/detraining plume model and its application in convective parameterization; J. Atmos. Sci. 47 2784-2802.

Kain J S and Fritsch J M 1993 Convective parameterization for mesoscale models: The Kain-Fritsch scheme; The Representation of Cumulus Convection in Numerical Models; Meteor. Monogr. No. 46, Amer. Meteor. Soc., pp. 165-170.

Kessler E 1969 On the distribution and continuity of water substance in atmospheric circulation; Meteor. Monogr. No. 32, Amer. Meteor. Soc., 84p.

Lin Y L, Farley R D and Orville H D 1983 Bulk parameterization of the snow field in a cloud model; J. Climate Appl. Meteor. 22 1065-1092.

Mlawer E J, Taubman S J, Brown P D, Iacono M J and Clough S A 1997 Radiative transfer for inhomogeneous atmospheres: RRTM, a validated correlated-k model for the long wave; J. Geophys. Res. 102D 16,663-16,682.

Rajeevan M, Kesarkar A, Thampi S B, Rao T N, Radhakrishna B and Rajasekhar M 2010 Sensitivity of WRF cloud microphysics to simulations of a severe thunderstorm event over southeast India; Ann. Geophys. 28 603-619.

Thompson G, Rasmussen R M and Manning K 2004 Explicit forecasts of winter precipitation using an improved bulk microphysics scheme. Part I: Description and sensitivity analysis; Mon. Weather Rev. 132 519-542.

Uma K N and Rao T N 2009 Characteristics of vertical velocity cores in different convective systems observed over Gadanki, India; Mon. Weather Rev. 137 954-975.

Yun-Fei F, Zhi-Wei H, Tian-Yi L, Zhong-Ping $\mathrm{S}$ and Yu W 2012 Evaluation of WRF Model hydrometeors based on TMI observations using an indirect method; Atmos. Ocean. Sci. Lett. 5(1) 32-37. 